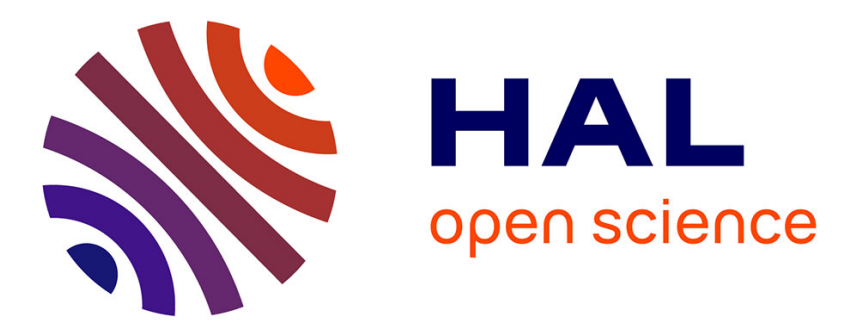

\title{
Importance of the decoration in shaped cobalt nanoparticles in the acceptor-less secondary alcohol dehydrogenation
}

Kamila Kaźmierczak, Raj-Kumar Ramamoorthy, A. Moisset, G. Viau, A. Viola, M. Giraud, Jennifer Peron, Lorette Sicard, J. Piquemal, M. Besson, et al.

\section{To cite this version:}

Kamila Kaźmierczak, Raj-Kumar Ramamoorthy, A. Moisset, G. Viau, A. Viola, et al.. Importance of the decoration in shaped cobalt nanoparticles in the acceptor-less secondary alcohol dehydrogenation. Catalysis Science \& Technology, 2020, 10 (15), pp.4923-4937. 10.1039/d0cy00390e . hal-02925855

\section{HAL Id: hal-02925855 https://hal.science/hal-02925855}

Submitted on 10 Nov 2020

HAL is a multi-disciplinary open access archive for the deposit and dissemination of scientific research documents, whether they are published or not. The documents may come from teaching and research institutions in France or abroad, or from public or private research centers.
L'archive ouverte pluridisciplinaire $\mathbf{H A L}$, est destinée au dépôt et à la diffusion de documents scientifiques de niveau recherche, publiés ou non, émanant des établissements d'enseignement et de recherche français ou étrangers, des laboratoires publics ou privés. 


\title{
Importance of the decoration in shaped cobalt nanoparticles in the acceptor-less secondary alcohol dehydrogenation
}

\begin{abstract}
Kamila Kaźmierczak, ${ }^{\mathrm{a}, \mathrm{b}}$ Raj Kumar Ramamoorthy, ${ }^{\mathrm{c}}$ Arthur Moisset, ${ }^{\mathrm{c}}$ Guillaume Viau, ${ }^{\mathrm{c}}$ Arnaud Viola, ${ }^{\mathrm{d}}$ Marion Giraud, ${ }^{d}$ Jennifer Peron, ${ }^{d}$ Lorette Sicard, ${ }^{d}$ Jean-Yves Piquemal, ${ }^{d}$ Michèle Besson, ${ }^{b}$ Noémie Perret, ${ }^{\mathrm{b}, *}$ Carine Michel ${ }^{\mathrm{a}, *}$

Metal catalysts are essential in the production of fuels and chemicals. Nonetheless, tailoring the exposed active sites to achieve the maximal theoretical conversion is still a great challenge. In the case of structure sensitive reactions, such as the attractive acceptor-less alcohol dehydrogenation, playing on the exposed metallic sites appears as an appealing strategy. Still, this approach requires advanced preparation protocols, and is even more difficult to implement for supported nonnoble metal catalysts which easily undergo sintering. Using the polyol method, we synthesized fourteen different cobalt catalysts, which consist of unsupported shaped nanoparticles stabilized by adsorbed carboxylate ligands. Their shape and the amount of ligands were characterized combining TEM and TGA- $\mathrm{N}_{2}$ measurements. These catalysts were found to be active in the 2-octanol dehydrogenation conditionally upon an organic layer limited to 1 to 2 monolayers. Moreover, they were fully selective towards desired ketone and $\mathrm{H}_{2}$. The active catalysts were stable, with no leaching or modification of the shape during the reaction. Periodic DFT computations predict a greater activity of the pristine opened type facet than of the compact one, but this is not confirmed experimentally with no clear correlation between the activity expressed in turnover number and the amount of a given type of site as quantified by TEM. Further modeling including the organic layer show that the presence of ligands reduces the sensitivity to the metallic structure. Nonetheless, these ligands generate a catalytic pocket, similar to the one found in enzymes, that interacts with the alcohol substrate through $\mathrm{H}$-bonding. This pocket is the most adapted to the alcohol dehydrogenation on the open type facet, which is mainly exposed on rods. This detailed understanding paves the way to an improved design of bespoke unsupported catalysts considering simultaneously the

structure and the nature of the ligand.
\end{abstract}

Received 00th January 20xx Accepted 00th January 20xx

DOI: $10.1039 / \mathrm{x} 0 \mathrm{xx} 00000 \mathrm{x}$

\section{Introduction}

For structure sensitive reactions, the performance of metal supported catalysts can be improved playing on the size of the metallic nanoparticles (NPs). ${ }^{1}$ In particular, low coordinated metallic sites can have a better catalytic ability than the high coordinated ones, and their relative concentration increases with the decrease of NPs size. For instance, corner sites were shown to be 200 times more active than terrace sites for $\mathrm{Au}$ supported over hydrotalcite (HT) for alcohol dehydrogenation, but they are also 4 times less present on NPs of $2 \mathrm{~nm}$ size and

\footnotetext{
a. Univ Lyon, ENS de Lyon, CNRS UMR 5182, Université Claude Bernard Lyon 1, Laboratoire de Chimie, 46 Allee d'Italie, 69342, Lyon, France

b. Univ Lyon, Université Claude Bernard Lyon 1, CNRS, UMR5256, IRCELYON, 2 avenue Albert Einstein, 69626, Villeurbanne, France

c. Université de Toulouse, LPCNO CNRS, INSA, UPS UMR 5215, 135 avenue de Rangueil, 31077 Cedex 4, Toulouse, France

d. Université de Paris, ITODYS, CNRS, UMR 7086, 15 rue J.-A. de Baïf, F-75013 Paris, France

*Corresponding authors: noemie.perret@ircelyon.univ-lyon1.fr and carine.michel@ens-lyon.fr

Electronic Supplementary Information (ESI) available: detailed synthesis protocols of cobalt nanoparticles, results of physic-chemical characterization, additional data connected with catalysts activity and DFT data. See DOI: 10.1039/x0xx00000x
}

almost 200 less on $12 \mathrm{~nm}$ size NPs. ${ }^{2}$ Obtaining supported NPs that are small enough (below $2 \mathrm{~nm}$ ) to expose a noticeable amount of low coordinated sites appears a difficult task when using conventional routes such as wet impregnation, especially when turning to abundant non-noble metals i.e. Co, $\mathrm{Ni}$ and $\mathrm{Cu} .3,4,5$ Another approach to increase the number of low coordinated metallic sites is to design NPs that are shaped to expose mainly open type facets. For instance, $\mathrm{Xu}$ et al. ${ }^{6}$ demonstrated that Ag nanocubes were much more active in the oxidation of styrene than near-spherical NPs (4 times more active) and platelets (14 times more active). This effect was related to a higher activity of $\mathrm{Ag}$ (100) open type facet, predominantly present on nanocubes, in comparison with $\mathrm{Ag}$ (111) close packed surface, present on both near-spherical NPs and platelets. Besides the activity, the selectivity can also be affected by the type of exposed surface. It was reported for benzene hydrogenation over Pt NPs, ${ }^{7}$ that Pt (100) surface favors complete hydrogenation to cyclohexane, while Pt (111) facet promotes partial hydrogenation to cyclohexene. These tailored NPs can be prepared with solvothermal or hydrothermal processes not only using noble, but also nonnoble metals. $8,9,10$ They were recently acknowledged as a 
promising new class of catalysts, yet still requiring more investigations and understanding. ${ }^{11,12,13,14}$

Nonetheless, these solvothermal preparations usually require the presence of ligands to stabilize and direct the NPs growth. ${ }^{15,16}$ If the NPs are not supported afterwards, those ligands are necessary to prevent aggregation in solution. Yet, the presence of ligands is very often found to be detrimental to the catalytic activity of metal NPs. For instance, $\mathrm{Au}_{25} / \mathrm{C}$ was shown to be less and less active in aerobic oxidation of benzyl alcohol as the dodecanethiolate surface coverage increased. ${ }^{17}$ The catalytic activity vanished once a full surface coverage was reached. However, ligands were also found to have a valuable impact in some cases, especially on reaction selectivity, ${ }^{18,19,20}$ a positive influence attributed to steric, ${ }^{21}$ orientation, ${ }^{22}$ and electronic ${ }^{23}$ effects. For example, the ligands density can limit the possible orientations of poly-functional molecules when accessing the catalytic sites. This was nicely illustrated recently by Medlin and co-workers on the hydrogenation of cinnamaldehyde on $\mathrm{Pt} / \mathrm{Al}_{2} \mathrm{O}_{3}$, a typical reaction where selectivity towards the unsaturated alcohol is key. When the catalyst was modified using 3-phenylpropanethiol ligands, ${ }^{22}$ the chemoselectivity of the reaction was considerably improved, with a raise of the selectivity towards unsaturated alcohol from $25 \%$ to $95 \%$. The limited access to the surface sites and the structural proximity of the cinnamyl aldehyde with the chosen ligand (3-phenylpropanethiol) were invoked to rationalize this strong improvement. The same strategy was later applied to the furfuryl alcohol hydrogenation. ${ }^{24}$ The desired hydrodeoxygenation to methylfuran is increased adjusting the thiolate ligand chain. Using Density Functional Theory (DFT), the thiolate ligands were found to suppress the unwanted decarbonylation route while stepped sites were still available for the sought hydrodeoxygenation. Computational investigations were key also to understand the differential impact of mono vs. bidentate phosphines on the decarbonylation of fatty alcohols to $\alpha$-olefins catalyzed by Pd. While the monodentate completely passivate the catalyst, the polydentate favored a highly selective activity. Ortuno and Lopez ${ }^{25}$ demonstrated that the higher flexibility of the bidentate ligands was essential to create catalytically active pockets.

To prepare decorated shaped NPs, the polyol method ${ }^{26}$ (one of the solvothermal protocols) appears as an appealing procedure that is able to generate a variety of shapes and is scalable to the preparation of several grams of powder per batch at laboratory scale. We recently focused on the preparation of Co NPs using it. ${ }^{27,28}$ By varying the preparation parameters, multiple shapes were obtained, like nanorods, ${ }^{27,29,30}$ nanowires, ${ }^{31}$ sea-urchinlike particles, ${ }^{27}$ cubic particles, ${ }^{27}$ hourglass-like particles ${ }^{30}$ and platelets. ${ }^{29,30}$ Combining experimental and periodic DFT investigations, we also rationalized the role of the carboxylate ligand in the shape control. ${ }^{29}$ Changing its concentration in the growth solution tunes its chemical potential and hence the relative stability of decorated crystallographic surfaces, and thereby the shape of the Co NPs.

Acceptor-less alcohol dehydrogenation is a very appealing reaction, since it is atom efficient and it leads to high-value added products, namely a ketone and $\mathrm{H}_{2} \cdot{ }^{32}$ However, it requires elevated temperature to proceed, and anaerobic atmosphere to adopt the desired acceptor-less mechanism. ${ }^{33}$ Many different supported noble and non-noble metal catalysts were reported as active in this reaction, i.e. $\mathrm{Pt}^{34} \mathrm{Pd},{ }^{35} \mathrm{Ru},{ }^{36,37} \mathrm{Re},{ }^{38} \mathrm{Rh},{ }^{39}$ $\mathrm{Au}, 2,40,41 \mathrm{Ag},{ }^{42,43,44,45} \mathrm{Cu}, 46,47,48,49 \mathrm{Ni}^{50,51}$ and $\mathrm{Co}^{52}$ Regarding the unsupported metal catalysts, Re NPs were reported as active towards acceptor-less alcohol dehydrogenation. ${ }^{53}$ Also, we have recently shown that Co nanorods stabilized by carboxylate (laurate) ligands have good catalytic properties for this reaction, with a high chemoselectivity, towards a broad substrate scope including linear and cyclic alcohols and a good recyclability ( 3 runs with no decrease in activity and selectivity and no modification of the anisotropic shape). ${ }^{54}$ The potentialities of these catalysts are clearly not fully exploited yet. Playing with the shape and the type of exposed facets appears as an interesting path to follow, since two very recent studies highlighted that the alcohol dehydrogenation reaction is structure sensitive on $\mathrm{Cu}$. He et al. ${ }^{55}$ showed that the $\mathrm{Cu}(211)$ stepped surface obtained after surface re-structuring of $\mathrm{Cu}$ supported catalysts exhibits a higher activity towards ethanol dehydrogenation than the close packed $\mathrm{Cu}(111)$ surface. Using periodic DFT calculations, Hoyt et al. ${ }^{56}$ demonstrated that dehydrogenation reaction intermediates are more strongly bonded on $\mathrm{Cu}(111) /(100)$ step edges than on $\mathrm{Cu}(111)$ surface. The related activation energies are also lower on step edges, making those sites clearly more active than the close packed surface sites.

To fully exploit the potentialities of decorated shaped NPs, improved understanding is needed to grasp the nature of the catalytic sites made of exposed (under)-coordinated metal atoms surrounded by organic ligands. In this work, we took advantage of the flexibility of the polyol process to prepare a variety of Co NPs decorated with carboxylate ligands and test these non-supported catalysts towards the 2-octanol dehydrogenation. The NPs shape was intentionally tuned to expose various facets in different amounts to probe the structure sensitivity of the alcohol dehydrogenation on Co. The carboxylate chain length was also modified to investigate its impact on the catalytic activity, following the work of Medlin and co-workers on the hydrogenation of cinnamaldehyde. ${ }^{22}$ Last, the influence of the presence of ligands on the exposed catalytic sites on the activity was rationalized through DFT computations.

\section{Materials and Methods}

\subsection{Synthetic procedures}

The list of all materials used is given in the supplementary information (SI) in section 1.1.

2.1.1. Preparation of cobalt precursors. Several cobalt (II) precursors were prepared with different long-chain carboxylates: heptanoate, octanoate, decanoate, laurate and palmitate, respectively denoted as $H, O, D, L$ and $P$. The detailed procedures are given in the SI. Briefly, it consists in reacting under vigorous stirring the desired carboxylic acid with a Co(II) salt in a basic $(\mathrm{NaOH})$ aqueous medium. Pink precipitates are 
recovered, washed with distilled water, and dried in an oven. Depending on the drying procedure, phases with different hydration states were obtained for the same carboxylate compound (SI).

2.1.2. Polyol syntheses of Co particles. Co particles with different sizes and shapes were synthesized following adapted procedures reported elsewhere. ${ }^{27}$ It consists in reacting a cobalt (II) carboxylate compound in a basic polyol (1,2-propanediol or 1,2-butanediol) at $175^{\circ} \mathrm{C}$ using $\mathrm{RuCl}_{3}$ as a seeding agent. The detailed procedures are given in the SI. The morphologies and mean dimensions of the particles can be varied depending on several reaction parameters such as the nature of the polyol, the nature of the $\mathrm{Co}$ (II) carboxylate, its drying procedure, the concentration of the carboxylate and the nature of the seeding agent (hydrated or anhydrous $\mathrm{RuCl}_{3}$ ). In this work, rods, diabolos and platelets were prepared. The following labelling scheme was chosen: type of ligand - shape - order number (when necessary), where the type of ligand indicates which carboxylate was used as a capping ligand (vide supra) and the shape corresponds to rods (R), diabolos (D) or platelets (P).

\subsection{Nanoparticles characterizations}

2.2.1. TEM. Transmission electron microscopy (TEM) characterizations were performed using a Jeol JEM-1011 instrument equipped with $\mathrm{L} \mathrm{LaB}_{6}$ filament and operating at 100 $\mathrm{kV}$. The images were collected with a $4008 \times 2672$ pixels CCD camera (Gatan Orius SC1000). The mean particle sizes were determined by a statistical analysis of at least 200 particles. All samples were prepared by evaporating a drop of diluted suspension in ethanol on a carbon-coated copper grid. Specific surface areas exposed by metal in the samples (SSA $)$ were calculated using the mean dimensions determined by TEM and assuming simple geometrical models, as explained in the SI.

2.2.2. TGA. TGA measurements were performed under $N_{2}$ to assess the mass of organic ligands of the catalysts $\left(\Delta \mathrm{m}_{\mathrm{TGA}-\mathrm{N}_{2}}\right)$. They were performed with TGA-DSC 1 Stare System Mettler Toledo apparatus, in the temperature range $20-1000^{\circ} \mathrm{C}$, using $10^{\circ} \mathrm{C} \mathrm{m^{-1 }}$ heating rate and $50 \mathrm{~mL} \mathrm{~min}^{-1}$ of total flow of gas.

2.2.3. XRD. X-ray diffraction analyses were carried out using a Panalytical X'pert pro diffractometer equipped with a Co anode $(\lambda \mathrm{K} \alpha=1.7889 \AA)$ and a X'celerator detector. The sizes of coherent diffraction domains were determined using MAUD software, ${ }^{57}$ which is based on the Rietveld method combined with Fourier analysis, and is well adapted for broadened diffraction peaks. Corrections for instrument broadening were made using a poly-crystalline silicon standard from Panalytical.

2.2.4. $\mathbf{N}_{2}$ physisorption. The specific surface area of the samples (cobalt nanoparticles covered with ligands) was measured by $\mathrm{N}_{2}$ physisorption at $77 \mathrm{~K}$ using an ASAP 2020 apparatus from Micromeritics. Surface area $\left(\mathrm{SSA}_{\mathrm{BET}}\right)$ was calculated using the Brunauer, Emmet and Teller (BET) equation in the relative pressure range (0.05-0.25). Before the analysis, samples were degassed under high vacuum ( $<150 \mathrm{mPa}$ ) for $12 \mathrm{~h}$ at $120^{\circ} \mathrm{C}$.

2.2.5. Surface coverage. For a given sample, the surface coverage with organic ligands was evaluated as the ratio between the amount of ligands ( $\mathrm{n}_{\text {ligands, }}$ in $\left.\mathrm{mol}\right)$ for a given mass ( $\left.\mathrm{m}_{\text {sample }}\right)$, as quantified by TGA, and the surface of exposed metallic Co (SA, in $\mathrm{m}^{2}$ ), for the same mass of sample, as derived from the TEM images analysis. The established accuracy of this value is \pm $2.5 \cdot 10^{-6} \mathrm{~mol} \mathrm{~m}^{-2}$.

$$
\begin{gathered}
\text { Surface coverage }=\frac{n_{\text {ligands }}}{\mathrm{SA}} \\
\mathrm{n}_{\text {ligands }}=\frac{\frac{\Delta \mathrm{m}_{\mathrm{TGA}-\mathrm{N}_{2}}}{100} \times \mathrm{m}_{\text {sample }}}{\mathrm{M}_{\text {ligands }}} \\
\mathrm{SA}=\mathrm{SSA}_{\mathrm{C}} \times\left(\frac{\left(100-\Delta \mathrm{m}_{\mathrm{TGA}-\mathrm{N}_{2}}\right)}{100} \times \mathrm{m}_{\text {sample }}\right)
\end{gathered}
$$

\subsection{Catalytic tests}

2.3.1. Catalytic tests conditions. Catalytic tests were performed to assess the activity of Co shaped NPs in the dehydrogenation of $( \pm)$-2-octanol in $\mathrm{n}$-decane. They were conducted for $24 \mathrm{~h}$ at $145^{\circ} \mathrm{C}$, using $25 \mathrm{mg}$ of catalyst ( $1 \mathrm{~mol} \%$ ) in $45 \mathrm{~mL}$ of liquids, with the alcohol concentration equal to $0.95 \mathrm{~mol} \mathrm{~L}^{-1}$, in a $100 \mathrm{~mL}$ semi-batch glass reactor with constant flow of inert gases $(90 \%$ Ar and $10 \% \mathrm{~N}_{2}$, total flow $30 \mathrm{~mL} \mathrm{~min}^{-1}$ ) and mechanical stirring (750 rpm). The reactor was coupled with a gas chromatograph (Shimadzu GC-2010, Supelco Carboxen-1010 PLOT column, thermal program: isotherm, $50^{\circ} \mathrm{C}, \mathrm{Ar}$ carrier gas, $\mathrm{TCD}$ detector) to quantify the $\mathrm{H}_{2}$ production during the course of experiment. Liquid aliquots of $0.50-0.75 \mathrm{~mL}$ were collected during the reaction, and further analysed by gas chromatography (Shimadzu, GC-2010, column ZB-FFAP, thermal program: gradient $40^{\circ} \mathrm{C} \rightarrow 230^{\circ} \mathrm{C}, 20^{\circ} \mathrm{C} \mathrm{min}{ }^{-1}$, isothermal $230^{\circ} \mathrm{C}, 10 \mathrm{~min}$, $\mathrm{N}_{2}$ carrier gas, FID detector), to measure the concentration of alcohol and of the corresponding carbonyl product (2octanone) in the reaction solution.

\subsubsection{Analysis of the catalytic tests results.}

Conversion of the substrate $X_{1}$ is defined as:

$$
X_{I}(\%)=\left(1-\frac{C_{x}}{C_{0}}\right) \cdot 100
$$

where:

$\mathrm{C}_{\mathrm{x}}$ - concentration of 2-octanol at a given time in liquid aliquots $\mathrm{C}_{\mathrm{o}}$ - concentration of 2-octanol at the beginning of reaction

Selectivity towards the corresponding ketone $\mathrm{S}_{\text {one }}$ is defined as:

$$
\mathrm{S}_{\text {one }}(\%)=\frac{\mathrm{C}_{2 \text {-octanone }}}{\mathrm{C}_{2 \text {-octanone }}+\sum \mathrm{n} \cdot \mathrm{C}_{\text {by-product }}} \cdot 100
$$

$\mathrm{C}_{2 \text {-octanone }}-$ concentration of 2-octanone at a given time in liquid aliquots

$\mathrm{n}$ - stoichiometric coefficient

$\mathrm{C}_{\text {by-product }}$ - concentration of byproduct(s) at a given time in liquid aliquots 
Reaction yield in 2-octanone $\mathrm{Y}_{\text {one }}$ is given by:

$$
\mathrm{Y}_{\text {one }}=\mathrm{X}_{1} \cdot \mathrm{S}_{\text {one }}
$$

The yield in $\mathrm{H}_{2} \mathrm{Y}_{\mathrm{H}_{2}}$ was also evaluated as:

$$
\mathrm{Y}_{\mathrm{H}_{2}}(\%)=\frac{\mathrm{n}_{\mathrm{H}_{2}}}{\mathrm{n}_{\text {theor }}} \cdot 100
$$

where:

$\mathrm{n}_{\mathrm{H}_{2}}$ - accumulated amount of $\mathrm{H}_{2}$, produced after given time of reaction

$\mathrm{n}_{\text {theor }}$ - theoretical amount of $\mathrm{H}_{2}$ possibly produced during the 2-octanol dehydrogenation reaction, based on the initial amount of alcohol.

The turnover number (TON) is calculated as:

$$
\text { TON }=\frac{\mathrm{n}_{\text {converted substrate }}}{\mathrm{n}_{\text {surface }} \text { Co atoms }}
$$

where:

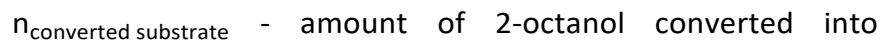
product(s) during the reaction, based on 2-octanol concentration at the beginning and end of the reaction

$\mathrm{n}_{\text {surface Co atoms }}$ - amount of surface Co (1 $1^{\text {st }}$ layer of metal) in the catalyst sample used in the reaction. This number was evaluated taking into account that the exposed facets exhibit different amount of Co atoms per surface unit (see SI, part 3, Table S1).

Established uncertainty of TON values is equal to \pm 25 molalcohol mol $_{\text {surface }} \mathrm{Co}^{-1}$.

2.3.3. Catalysts pre-treatments. In an attempt to increase the catalysts activity, different pre-treatment procedures were applied before the reactions:

Thermal treatment under vacuum

Around $100 \mathrm{mg}$ of a catalyst was placed into a glass cell, which subsequently was connected to the vacuum system. After reaching a high vacuum $(<150 \mathrm{mPa})$, the temperature program was started $\left(10^{\circ} \mathrm{C} \mathrm{min}^{-1}, 120^{\circ} \mathrm{C}, 12 \mathrm{~h}\right)$ to desorb the ligands from the catalyst.

Washing with ethanol of a dried sample

Around $100 \mathrm{mg}$ of a dried catalyst were introduced into a centrifugation vial ( $5.0 \mathrm{~mL}$ volume) and $3.0 \mathrm{~mL}$ of ethanol was added. After few minutes of shaking, the sample was centrifugated (5000 rpm, $10 \mathrm{~min}$ ) and the supernatant was collected. This washing was repeated 3 times. Then, the sample was dried for $24 \mathrm{~h}$ in an oven $\left(80^{\circ} \mathrm{C}, \mathrm{N}_{2}\right.$ atmosphere).

$\mathrm{H}_{2}$ in situ pre-treatment

$25 \mathrm{mg}$ of a catalyst and $30.0 \mathrm{~mL}$ of decane were introduced into the reactor. All the reaction equipment was connected and the suspension was heated up to $145^{\circ} \mathrm{C}$. Once the target temperature was reached, the suspension was treated for $1 \mathrm{~h}$ with a mixture of flowing gases: $10 \mathrm{~mL} \mathrm{~min}^{-1} \mathrm{H}_{2}+30 \mathrm{~mL} \mathrm{~min}-1$ inert gases, and for the next $1 \mathrm{~h}$ only with $30 \mathrm{~mL} \mathrm{~min}^{-1}$ of inert gases, to remove the remaining $\mathrm{H}_{2}$ from the reactor. After this, a solution of 2-octanol in decane $(15 \mathrm{~mL})$ was added into the reactor to reach a final volume of a reaction solution of a concentration of $0.95 \mathrm{~mol} \mathrm{~L}^{-1}$ of 2-octanol in decane and the reaction was started.
Additional washing during the synthesis of the catalysts

The chosen catalysts (P-R-2 and P-P) were re-synthesized and modified washing procedures before drying were applied. The P-R-2 sample was washed 6 times with $120 \mathrm{~mL}$ of methanol, instead of 3 times with $100 \mathrm{~mL}$ of ethanol. The P-P sample was washed 12 times with $120 \mathrm{~mL}$ of methanol, instead of 3 times with $120 \mathrm{~mL}$ of ethanol.

2.3.4. Post-reaction analysis. To check the cobalt leaching from the NPs to the solution during the reaction, the final reaction solutions were analyzed by ICP-OES (Inductively Coupled Plasma - Optical Emission Spectroscopy) using the ACTIVA Jobin Yvon apparatus. The detection limit of Co was $0.2 \mathrm{mg} \mathrm{L}^{-1}$.

\subsection{Computational details}

Vienna $A b$ initio Simulation Package (VASP) computer program was used to perform periodic spin polarized Density Functional Theory (DFT) calculations. ${ }^{58}$ Potential and the exchange correlation were calculated with the generalized gradient approximation (GGA), using PBE functional59 with $\mathrm{dDsC}$ dispersion correction. ${ }^{60,61}$ A cut-off energy of $400 \mathrm{eV}$ was applied to obtain a tight convergence of the plane-wave expansion. The projector augmented wave method (PAW) ${ }^{62,63}$ was used to describe the electron-ion interactions. The SCF convergence criterium was set at $10^{-6} \mathrm{eV}$.

A $p(3 \times 3)$ cell for $(0001)$ surface and a $p(4 \times 4)$ for (11-20) surface were considered using a four-layer slab and over $15 \AA$ of vacuum. A dipole correction in the $z$ direction was included. For the Brillouin zone integration, a Monkhorst-Pack mesh of $3 \times 3 \times 1 \mathrm{~K}$-points was used. ${ }^{64}$ The two bottom layers of the slabs were kept fixed to the bulk-truncated positions (with a Co-Co interatomic distance of $2.47 \AA$, the experimental value being equal to $2.51 \AA$ ) while the two upper layers were allowed to relax. Adsorption and reaction processes were realized on the upper surface of the slab. Structures were allowed to relax until the forces were lower than $0.015 \mathrm{eV} \AA^{-1} .1 .63 \mu \mathrm{B}$ per atom was used as an initial magnetic moment value for $\mathrm{Co}$ and it turned to $1.58 \mu \mathrm{B}$ and $1.78 \mu \mathrm{B}$ for (0001) and (11-20) surfaces, respectively. It oscillated slightly $( \pm 0.05 \mu \mathrm{B})$ along the reaction pathways for all the considered surfaces.

Frequencies were computed numerically within the harmonic approximation. Nudge elastic band procedures (NEB) $)^{65,66}$ together with the reaction path generator developed by $P$. Fleurat-Lessard, Opt'n Path, ${ }^{67}$ were used to determine the transition state structures. They were further optimized using the dimer method ${ }^{68,69}$ and confirmed by the presence of a single imaginary frequency whose normal mode corresponds to the reaction coordinate.

Gibbs energies are derived from the electronic energies within the perfect gas model, the rigid rotator and harmonic oscillator approximations for molecules and the lattice gas for adsorbates. In other words, for molecules in gas phase, Gibbs free energy $G$ is calculated as follow:

$$
\mathrm{G}=\mathrm{E}_{\mathrm{ele}}+\mathrm{nk_{ \textrm {B } }} T+\mathrm{ZPE}-\mathrm{T} \times\left(\mathrm{S}_{\mathrm{t}}+\mathrm{S}_{\mathrm{r}}+\mathrm{S}_{\mathrm{vib}}\right)
$$

with:

$\mathrm{E}_{\text {ele }}$ - electronic energy

$n=4$ for non-linear molecules and $n=3.5$ for linear molecules 
$\mathrm{k}_{\mathrm{B}}-$ Boltzmann constant

$\mathrm{T}$ - temperature, equal to $145^{\circ} \mathrm{C}(418 \mathrm{~K})$

ZPE - zero-point energy

$\mathrm{S}_{\mathrm{t}}, \mathrm{S}_{\mathrm{r}}, \mathrm{S}_{\mathrm{vib}}$ - translational, rotational and vibrational entropy components

Adsorbates are considered to lose their rotational and translational degrees of freedom and have a diffusion energy that is higher than the thermal energy. Hence, their Gibbs free energies are considered as follow:

$$
\begin{aligned}
\mathrm{G}_{\text {slab }} & =\mathrm{E}_{\text {ele }}+\mathrm{ZPE}-\mathrm{T} \times \mathrm{S}_{\text {vib }} \\
\mathrm{G}_{\mathrm{ads} / \mathrm{slab}} & =\mathrm{E}_{\text {ele }}+\mathrm{ZPE}-\mathrm{T} \times \mathrm{S}_{\text {vib }}
\end{aligned}
$$

$\mathrm{G}_{\text {slab }}-$ Gibbs free energy of slab

$\mathrm{G}_{\mathrm{ads} / \mathrm{slab}}-\mathrm{Gibbs}$ free energy of the species adsorbed on a slab.

ZPE and $\mathrm{S}_{\mathrm{vib}}$ are based on the harmonic vibration of the adsorbate.

Frequencies lower than $50 \mathrm{~cm}^{-1}$ were neglected for all the entropy calculations.

The Gibbs free energy of adsorption $\left(G_{a d s}\right.$ ) for a given state was calculated as the difference between the energy of molecule adsorbed on the surface and that of molecule in gas phase and of the surface, depending on the case. A negative energy means a stabilizing adsorption.

For both surfaces, the presence of co-adsorbed $\mathrm{CH}_{3} \mathrm{COO}$ ligands during the reaction, used to mimic the presence of the longer chain carboxylate ligands present on NPs surfaces, was considered. On the (0001), for $p(3 \times 3)$, the reaction was modeled in the presence of two ligands, what corresponds to the surface coverage of $\theta=4 / 9 \mathrm{ML}\left(0.44 \mathrm{ML}, 6.98 .10^{-6} \mathrm{~mol} \mathrm{~m}^{-2}\right.$ ). For (11-20) facet, with $p(4 \times 4)$, the presence of three ligands on the surface was considered, what corresponds to the coverage of $\theta=3 / 4 \mathrm{ML}$ (0.75 ML, 7.26.10-6 $\mathrm{mol} \mathrm{m}^{-2}$ ).

\section{Results and discussion}

In this work, the catalytic properties of unsupported Co NPs with different shapes were evaluated for the acceptor-less dehydrogenation of model secondary alcohol (2-octanol) and their activity was correlated with the intrinsic properties of the samples. The particles were prepared by polyol method, using long-chain carboxylate ligands, which are adsorbed onto the different crystal facets defining the particle morphology. ${ }^{29}$ Two main factors were considered as guiding the catalysts performance: type and percentage of exposed facets and surface coverage with ligands. From one side, if the reaction is shape-sensitive, then a relation between the morphology and activity should be observed. On the other hand, presence of ligands can lower the catalysts activity by limiting the number of accessible sites, or even deactivate the catalyst.

\subsection{Preparation and characterization of the NPs}

Three sets of unsupported Co catalysts with different morphologies, i.e. nanorods (R), diabolos (D) and platelets ( $P$ ), were prepared. ${ }^{70}$ In the first series, Co nanoparticles of various shapes were decorated with C12 laurate ligand (L). In the second series, NPs of different shapes were also prepared, but the carbon chain length was increased to 16 using palmitate ligand $(P)$. Finally, the shorter chains $C 7$ heptanoate $(H), C 8$ octanoate (O) and C10 decanoate (D), were used to prepare nanorods exclusively. The samples are named according to: type of ligand - shape - order number (when necessary). The detailed synthesis procedures are reported in the $\mathrm{SI}$, and the characterization results are gathered in Table 1.

Representative TEM images of Co particles prepared with the

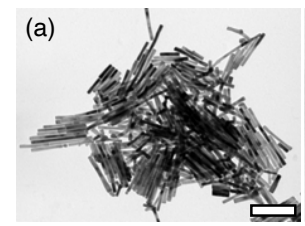

$\mathrm{d}_{\mathrm{TEM}}=19 \mathrm{~nm} ; \mathrm{L}_{\mathrm{TEM}}=175 \mathrm{~nm}$ $\mathbf{L}_{\mathrm{TEM}}$ (b)

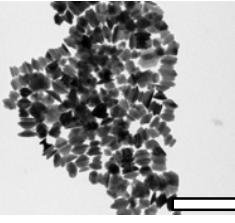

$D_{\text {TEM }}=46 \mathrm{~nm} ; L_{\text {TEM }}=39 \mathrm{~nm}$ $\mathrm{d}_{\text {TEM }}=\mathbf{2 1} \mathbf{n m}$
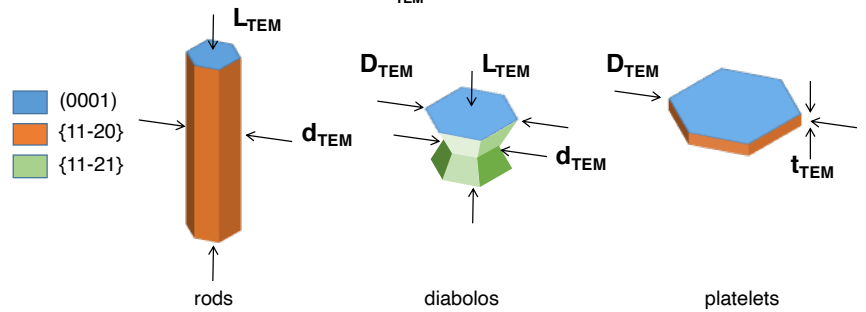

platelets
Figure 1. TEM images for Co NPs with different shapes, protected with laurate ligands and their respective geometrical models: (a) rods, L-R, (b) diabolos, L-D and (c) platelets, L-P. The scale bar stands for $200 \mathrm{~nm}$. $\mathrm{L}_{\text {TEM }}$ - mean length; $\mathrm{D}_{\text {TEM }}$ - mean diameter of the diabolos tips and of the platelets; $d_{\text {TEM }}$ - mean diameter of the rods and of the central column in the diabolos; $t_{\text {TEM: }}$ mean thickness of the platelets.

laurate ligand as well as their corresponding geometrical models are given in Figure 1 (see Figures S1, S2 and S3 for TEM images of all the Co samples prepared in this work). The length of nanorods varies in the range of $\mathrm{L}_{\mathrm{TEM}}=35-187 \mathrm{~nm}$, while their diameter is in the range of $d_{\text {TEM }}=13-26 \mathrm{~nm}$. Diabolos show inner diameter of $d_{\text {TEM }}=17-21$, outer diameter of $D_{\text {TEM }}=25-46 \mathrm{~nm}$, and length of 23-39 $\mathrm{nm}$. For platelets, the diameter is equal to $56-$ $57 \mathrm{~nm}$, and their thickness is of 8-12 nm. Three types of crystal facets are encountered in these particles: (0001) compact planes and open $\{11-20\}$ and $\{11-21\}$ facets, their relative proportions depending on the nanocrystal morphology. Typically, around $90 \%$ of the surface of Co rods correspond to \{11-20\} facets, the last $10 \%$ to (0001) planes, while the surface corresponding to $\{11-21\}$ facets, if any, can be neglected in most cases (see Table 1). The distinction between rods and diabolos is not straightforward since diabolos can be seen as rods with extended hexagonal-based conical heads (named "tip" in the brief description in Table 1). Noticeably, L-R-3 sample can be seen as an intermediate case, that is considered as a nanorods with large tips (see Figure S1, supporting information). Particles with a high proportion of $\{11-21\}$ and (0001) facets are denoted diabolos, while the rods mainly exhibit $\{11-20\}$ planes. For diabolos, two different types of facets are exposed: (0001) and \{11-21\}, corresponding respectively to ca. $40 \%$ and $60 \%$ of the total surface of NPs, respectively. Platelets expose mainly close packed (0001) facets, corresponding to ca. $70-80 \%$ of the NP surface, while the rest of the surface corresponds to $\{11-20\}$ facets. 
The particles were further characterized by powder X-ray diffraction (see Figure S5). Co rods crystallize with the pure hcp structure, while the native $\mathrm{CoO}$ phase can be hardly detected. It has previously been shown that this phase is generated when the particles are exposed to air, it is polycrystalline and has a thickness of about $1.5 \mathrm{~nm} .{ }^{71}$ Diabolos and platelets crystallize also mainly with the hcp structure, but the fcc phase can also be detected, especially for the platelets.

Based on the geometric measurements from the TEM images, the specific surface areas of $\mathrm{Co}\left(\mathrm{SSA}_{\mathrm{C}}\right)$ were calculated for each sample (for the details see $\mathrm{SI}$, part 2.3.). The values are in the range 22-47 $\mathrm{m}^{2} \mathrm{~g}^{-1}$ (see Table 1 ), the lowest being for $\mathrm{O}-\mathrm{R}$ sample, and the highest for P-R-3 sample. However, no tendency between the shape and the exposed surface area is visible. The specific surface area of the samples (SSA $A_{B E T}$ of the metal NPs covered with ligands) was measured by $\mathrm{N}_{2}$ physisorption for L-R-1 and L-R-2 samples. SSAs from the two measurements were in very good agreement for the first sample $\left(\mathrm{SSA}_{\mathrm{C}}\right.$ and $\left.\mathrm{SSA}_{\mathrm{BET}}=29 \mathrm{~m}^{2} \mathrm{~g}^{-1}\right)$ but they differed for the second sample $\left(\mathrm{SSA}_{\mathrm{C}}=26 \mathrm{~m}^{2} \mathrm{~g}^{-1}\right.$ and $\left.\mathrm{SSA} \mathrm{BET}=32 \mathrm{~m}^{2} \mathrm{~g}^{-1}\right)$ which implies that the SSA of exposed metal surfaces assessed by $\mathrm{N}_{2}$ physisorption cannot be determined confidently as it can be influenced by the presence of ligands on NPs surfaces. In order to assess the exposed surface area of metal, the geometric measurements based on TEM analysis should be more suitable. Since carboxylate ligands are adsorbed onto the particle surface, $^{72}$ TGA experiments were performed in order to determine the different amounts of organic matter for all the Co particles. The decomposition of carboxylate ligands occurs at about $300^{\circ} \mathrm{C}$ and is associated with an endothermic peak (see Figure S6, SI). The weight loss is in the range $6.4-62.5 \%$, depending on the nature of the Co catalyst (see Table 1). These data indicate that the particles display different thicknesses of ligand coverages. The ligand surface coverages were calculated based on the molar amount of ligands quantified by TGA and the exposed metal surface area, based on TEM geometric measurements (see Experimental part, Nanoparticles characterization, Surface coverage). The calculated values are in the range of $17-167 \cdot 10^{-6} \mathrm{~mol} \mathrm{~m}^{-2}$. Based on the area of surface unit cell for a given facet (from the crystallographic cleavage of bulk metal) and maximum number of ligands adsorbed (1 carboxylic ligand is considered to be adsorbed onto 2 surface Co atoms), one monolayer ( $\mathrm{ML}$ ) of ligands is equivalent to $16 \cdot 10^{-6}$ $\mathrm{mol} \mathrm{m} \mathrm{m}^{-2}$ on the close packed (0001) surface, to $10 \cdot 10^{-6} \mathrm{~mol} \mathrm{~m}^{-2}$ on (11-20) and to $18 \cdot 10^{-6} \mathrm{~mol} \mathrm{~m}^{-2}$ on (11-21) open type facets. This clearly indicates that the organic protecting layer thickness corresponds to at least 1-2 ML (or 1 bilayer), and in some cases, it can reach up to $10 \mathrm{ML}$.

In brief, 14 different Co NPs were synthesized by the polyol method, using carboxylate ligands of increasing chain length (from C7 to C16). They expose three main types of facets ((0001), $\{11-20\}$ and $\{11-21\})$ in various proportions depending on their shape as determined by TEM. Based on TGA analyses combined with the specific surface area derived from TEM analysis, the thickness of the organic layers used to stabilize these NPs ranges 1-10 ML, depending on the samples. Their variety will allow further to investigate the influence of several factors on the catalytic activity: (i) type of capping ligand (ii) thickness of the organic layer (iii) structure sensitivity of the alcohol dehydrogenation reaction.

Table 1. Characterization of unsupported shaped Co nanoparticles obtained by polyol synthesis method.

\begin{tabular}{|c|c|c|c|c|c|c|c|c|}
\hline \multirow[b]{2}{*}{ Sample $^{1}$} & \multirow[b]{2}{*}{ Ligand } & \multirow[b]{2}{*}{ Shape } & \multicolumn{3}{|c|}{ Exposed facets } & \multirow{2}{*}{$\begin{array}{l}\operatorname{SSAc}^{2} \\
\left(\mathrm{~m}^{2} \mathrm{~g}^{-1}\right)\end{array}$} & \multirow{2}{*}{$\begin{array}{c}\Delta \mathrm{m}_{\mathrm{TGA}-\mathrm{N}_{2}}{ }^{3} \\
(\mathrm{wt} \%)\end{array}$} & \multirow{2}{*}{$\begin{array}{c}\text { Surface coverage } \\
\left(\mathrm{mol} \cdot \mathrm{m}^{-2} \cdot 10^{-6}\right)\end{array}$} \\
\hline & & & $\begin{array}{c}(0001) \\
(\%)\end{array}$ & $\begin{array}{c}(11-20) \\
(\%)\end{array}$ & $\begin{array}{c}(11-21) \\
(\%)\end{array}$ & & & \\
\hline L-R-1 & Laurate & Nanorods & 5 & 95 & 0 & 29 & 9.6 & 18 \\
\hline L-R-2 & Laurate & Nanorods & 6 & 94 & 0 & 26 & 10.2 & 22 \\
\hline L-R-3 & Laurate & $\begin{array}{l}\text { Short nanorods } \\
\text { with large tips }\end{array}$ & 35 & 20 & 45 & 39 & 28.4 & 51 \\
\hline L-R-4 & Laurate & $\begin{array}{l}\text { Nanorods } \\
\text { without tips }\end{array}$ & 6 & 94 & 0 & 39 & 11.4 & 17 \\
\hline L-D & Laurate & Diabolos & 38 & 0 & 62 & 27 & 10.9 & 23 \\
\hline L-P & Laurate & Platelets & 78 & 22 & 0 & 36 & 12.0 & 19 \\
\hline P-R-1 & Palmitate & Long nanorods & 5 & 95 & 0 & 27 & 41.2 & 102 \\
\hline P-R-2 & Palmitate & Short nanorods & 8 & 92 & 0 & 35 & 31.9 & 52 \\
\hline P-R-3 & Palmitate & $\begin{array}{l}\text { Very short } \\
\text { nanorods }\end{array}$ & 14 & 86 & 0 & 47 & 59.7 & 123 \\
\hline P-D & Palmitate & Diabolos & 35 & 0 & 65 & 39 & 62.5 & 167 \\
\hline $\mathbf{P}-\mathbf{P}$ & Palmitate & Platelets & 67 & 33 & 0 & 28 & 44.4 & 112 \\
\hline H-R & Heptanoate & Nanorods & - & - & - & - & 9.7 & - \\
\hline O-R & Octanoate & Nanorods & 8 & 92 & 0 & 22 & 6.4 & 22 \\
\hline D-R & Decanoate & Nanorods & 5 & 95 & 0 & 23 & 8.4 & 23 \\
\hline
\end{tabular}

1Samples are named according to: type of ligand - shape - order number (when necessary)

${ }^{2} S S A_{C}$ - Calculated specific surface area of metal in a sample, based on TEM geometric measurements

${ }^{3}$ Weight loss according to TGA- $\mathrm{N}_{2}$ measurements, equal to the mass of organic ligands in the sample 


\subsection{Catalytic activity of shaped Co NPs}

All the decorated shaped Co nanoparticles were tested as catalysts in the 2-octanol dehydrogenation using a semi-batch reactor to shift the unfavorable reaction equilibrium towards the products. The corresponding results are gathered in Table 2. Figure 2 illustrates typical results of a catalytic test using sample L-R-1: (a) conversion of 2-octanol, yield in $\mathrm{H}_{2}$ and yield in 2-octanone as a function of time, (b) intensity of $\mathrm{H}_{2}$ production during the course of the reaction. For all the catalytic tests, the two yields are in relatively good agreement within $6 \%$, and the selectivity towards the production of the ketone and hydrogen is nearly quantitative, confirming the acceptor-less mechanism of the reaction. The $\mathrm{H}_{2}$ production increased gradually at the beginning of the reaction, to reach a maximum after few hours and then dropped gradually. The gradual increase at the beginning of the reaction signalized an induction period to fully activate the catalyst, while the large drop at rather low conversion (below 20\%) can be related to a possible partial poisoning of the surface. A possible explanation of the induction period is the presence of Co oxide surface layer that has to be reduced first to lead to the active catalyst. To verify this, the experiment was conducted with in situ $\mathrm{H}_{2}$ pretreatment of the catalyst before the reaction. In this case, the $\mathrm{H}_{2}$ production started immediately and intensively, confirming the presence of a small passivation layer. This test also shows that this layer does not influence the overall performance of the catalyst (see Table 2, sample L-R-1 ${ }^{\text {a) }}$ and illustrates the reproducibility of the catalytic tests, within the experimental error (conversion $\pm 3 \%$ ).

Table 2. Catalytic results after $24 \mathrm{~h}$ of reaction for 2-octanol dehydrogenation using Co shaped nanoparticles decorated with various carboxylate ligands. Reaction conditions: 2-octanol $\left(0.95 \mathrm{~mol} \mathrm{~L}^{-1}\right)$, decane, $145^{\circ} \mathrm{C}$, inert atm, $\mathrm{m}_{\text {catalyst }}=25 \mathrm{mg}, \mathrm{n}_{\text {alcohol }}: \mathrm{n}_{\text {catalyst }}=100$.

\begin{tabular}{|c|c|c|c|c|}
\hline Sample & $X_{I}(\%)$ & $Y_{\text {one }}(\%)$ & $\mathbf{Y}_{\mathrm{H}_{2}}(\%)$ & 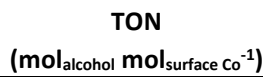 \\
\hline L-R-1 & 35 & 35 & 30 & 1140 \\
\hline L-R-1 ${ }^{a}$ & 33 & 33 & 27 & 1080 \\
\hline L-R-2 & 32 & 32 & 27 & 1170 \\
\hline L-R-3 & 4 & 4 & 2 & 70 \\
\hline L-R-4 & 34 & 34 & 28 & 830 \\
\hline L-D & 32 & 32 & 30 & 610 \\
\hline L-P & 35 & 35 & 33 & 600 \\
\hline P-R-1 & 2 & 2 & 1 & 90 \\
\hline P-R-2 & 3 & 3 & 1 & 100 \\
\hline P-R-3 & 9 & 9 & 7 & 350 \\
\hline P-D & 1 & 1 & 1 & 70 \\
\hline P-P & 16 & 16 & 15 & 430 \\
\hline H-R & 22 & 22 & 17 & n.a. \\
\hline O-R & 23 & 23 & 19 & 890 \\
\hline D-R & 25 & 25 & 23 & 970 \\
\hline
\end{tabular}

a - experiment performed with in situ $\mathrm{H}_{2}$ pre-treatment of catalyst

n.a. - not available, due to a poor definition of the shape and distribution of the corresponding nanoparticules

Within the set of 14 samples, all catalysts exhibit a quantitative selectivity toward 2-octanone, in line with what have been reported for several metal supported heterogeneous catalysts, regardless of the metal used. $37,38,40,42,45,47,49,50,52,53,54$ When the
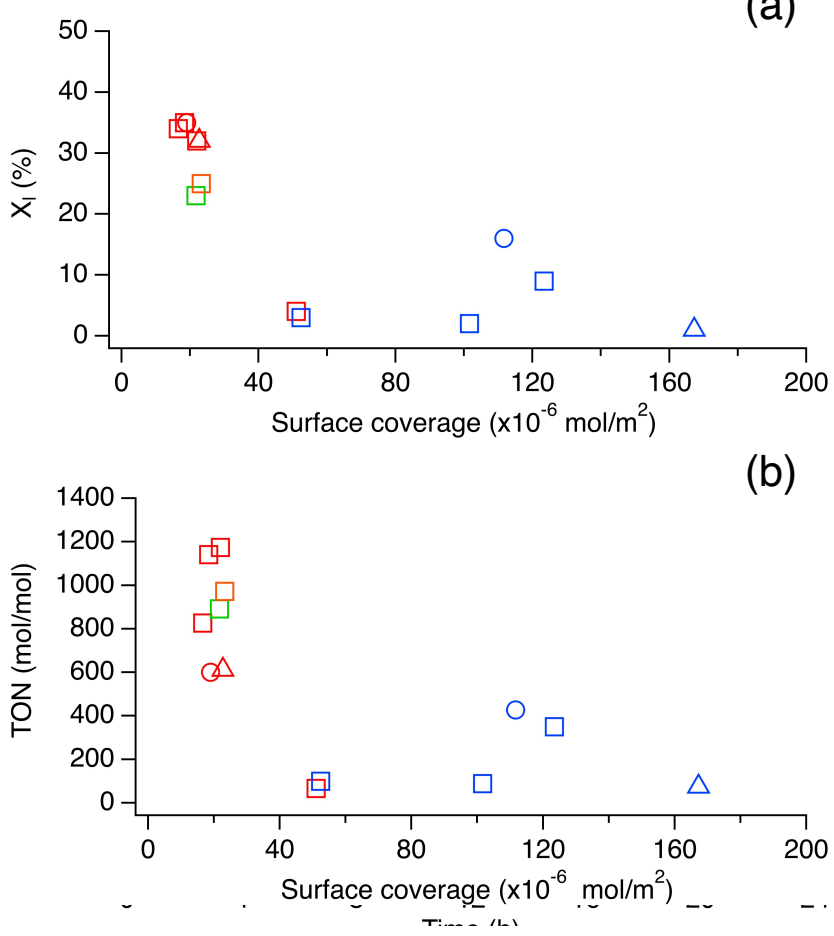

Figure 3. (a) 2-octanol conversion ( $\mathrm{X}_{1}, \%$ ) and (b) turn-over number (TON, $\mathrm{mol} \mathrm{mol}^{-1}$ ) as a function of the surface coverage. The points correspond to the Co nanoparticles (Table 1, FTable 2): nanorods $(\square)$, diabolos $(\triangle)$, platelets $(O)$. The color of the symbols represents (the type of decorating ligand: palmitate (blue), laurate (red), decanoate (orange), zoctanoate (green).

laurate was used as a ligand (first series of catalysts) the corresponding catalysts showed similar catalytic activity (conversion 32-35\%) except short nanorods (L-R-3, conversion of $4 \%$ ). In the second series, all Co nanoparticles protected by palmitate were poorly or not active towards 2-octanol dehydrogenation. Only platelets (P-P) and very short nanorods (P-R-3) gave $16 \%$ and $9 \%$ of conversion, respectively. For the last series of catalysts, i.e. nanorods protected with carboxylates of different carbon chain length ( $C 7, C 8, C 10)$, a similar 2-octanol conversion was observed, from $22 \%$ to $25 \%$. This conversion is lower than the one obtained with the laurate nanorods (L-R-1, L-R-2 and L-R-4) or other shaped nanoparticles covered by laurate (L-D, L-P). In short, nanorods with laurate ligands demonstrated the best performance, giving conversions of over $10 \%$ higher than those of nanorods protected with ligands of other chain lengths.

It is worth to notice that the highest conversion obtained in this work (35\%) is lower than the one reported previously for Co nanorods decorated with laurate ligands and the same alcohol substrate (85\%). ${ }^{54}$ This is easily explained by the use of solventfree conditions and a higher temperature of $180^{\circ} \mathrm{C}$. To compare the performance of our catalysts with those reported in the literature is not straightforward, as the reaction conditions such as the temperature, the presence of a solvent, and metal to alcohol ratio can differ significantly. To partly overcome these discrepancies the turnover number (TON) can be used to express the catalysts activity. It is easier to report TON values by considering the total amount of metal atoms since assessing the number of surface atoms can be tedious and challenging. In this 
case the TON value for our best Co nanocatalyst in term of conversion (L-R-1) is equal to $39 \mathrm{~mol}_{\text {alcohol }}$ mol $_{\text {total }} \mathrm{Co}^{-1}$ after $24 \mathrm{~h}$ of reaction. It remains of the same order of magnitude as that of noble Re NPs (TON of 50) 53 and $\mathrm{Co} / \mathrm{TiO}_{2}$ (78)..$^{52}$ Also, it is higher than that for $\mathrm{Ag} / \mathrm{Al}_{2} \mathrm{O}_{3}(25),{ }^{45} \mathrm{Cu} /$ hydrotalcite $(13)^{47}$ and $\mathrm{Ru} / \mathrm{AIO}(\mathrm{OH})(22),{ }^{37}$ for this peculiar substrate. To better analyse the performance of our catalysts in term of morphology and exposed sites, the activity was expressed by TON, scaled using the number of Co exposed at the catalyst surface and measured after $24 \mathrm{~h}$ to limit the bias likely to be induced by the variable induction period. The TON values are ranging from 70 to 1170 molalcohol mol surface $\mathrm{Co}^{-1}$, being the lowest for L-R-3 and the highest for L-R-2 samples, respectively. With this analysis, no correlation between the catalysts activity and morphology of samples was observed, hence the structure sensitivity was not revealed. See Figure S7 for the graphs relating TON with the type and amount of exposed Co surfaces.

\subsection{Importance of the ligands}

Surface coverage with ligands is another important structural feature of the present unsupported shaped Co nanoparticles. When comparing this value (Table 1 ) and the catalytic activity of the nanoparticles (Table 2), it is easily noticed that a high coverage is detrimental to the catalytic performance. For instance, L-R-3 has a similar shape as L-R-1 or L-R-2, but it shows a much higher surface coverage ( $x 3$ times) and a much lower conversion in 2 -octanol ( $4 \%$ vs. $32-35 \%$ ). This is highlighted when plotting the conversion of 2-octanol as a function of the coverage (Figure 3a) or even better the TON (Figure 3b). Two groups of catalysts are evident. In the first one, the coverage is around $20 \cdot 10^{-6} \mathrm{~mol} \mathrm{~m}^{-2}$, what is equivalent to $1-2$ monolayers or 1 bilayer of ligands, and the conversion is above $20 \%$ and the corresponding TON is above $500 \mathrm{~mol} \mathrm{~mol}^{-1}$. In the second group, the coverage is above $50 \cdot 10^{-6} \mathrm{~mol} \mathrm{~m}^{-2}$ and the catalytic activities reported are much lower (conversion below 20\% and TON below $500 \mathrm{~mol} \mathrm{~mol}^{-1}$ ). Therefore, a too thick organic layer prevents the catalytic activity, probably by limiting the access of the substrate to the catalyst surface. This was already reported in the literature, for the aerobic oxidation of benzyl alcohol with $\mathrm{Au}_{25}$ clusters supported on carbon. ${ }^{17}$ The catalysts uncoated with thiolate ligands showed higher activity than the coated ones and the catalytic activity decreased with increasing amount of thiolate on the metal surface. After the surface was fully covered, the activity was entirely suppressed. Such a behavior was also observed for $\mathrm{Pd} / \mathrm{Al}_{2} \mathrm{O}_{3} .{ }^{73}$

In the attempts to decrease the amount of ligand of the poorly or non-active catalysts, several pre-treatments were conducted

\begin{tabular}{|c|c|c|c|c|c|}
\hline Sample & $\begin{array}{c}\text { Pre- } \\
\text { treatment }\end{array}$ & $X_{I}(\%)$ & $\begin{array}{l}\Delta \mathrm{m}_{\mathrm{TGA}-\mathrm{N}_{2}} \\
{ }^{1}(\mathrm{wt} \%)\end{array}$ & $\begin{array}{c}\text { Surface } \\
\text { coverage } \\
\left(\mathrm{mol} \mathrm{mol}^{-2} 10^{-6}\right)\end{array}$ & $\begin{array}{c}\text { TON } \\
\left(\mathrm{mol}_{\text {alcohol }}\right. \\
\text { mol }_{\left.\text {surface } \mathrm{Co}^{-1}\right)}\end{array}$ \\
\hline \multirow{2}{*}{ L-R-3 } & --- & 4 & 28.4 & 51 & 70 \\
\hline & 1 & 1 & 30.9 & 62 & 0 \\
\hline \multirow{5}{*}{ P-R-2 } & --- & 3 & 31.9 & 52 & 100 \\
\hline & 1 & 1 & 32.1 & 53 & 10 \\
\hline & 2 & 1 & 30.4 & 49 & 0 \\
\hline & 3 & 4 & n.a. & n.a. & 120 \\
\hline & 4 & 19 & 12.3 & 22 & 620 \\
\hline \multirow{2}{*}{ P-P } & --- & 16 & 44.4 & 112 & 430 \\
\hline & 4 & 55 & 16.4 & 19 & 990 \\
\hline
\end{tabular}
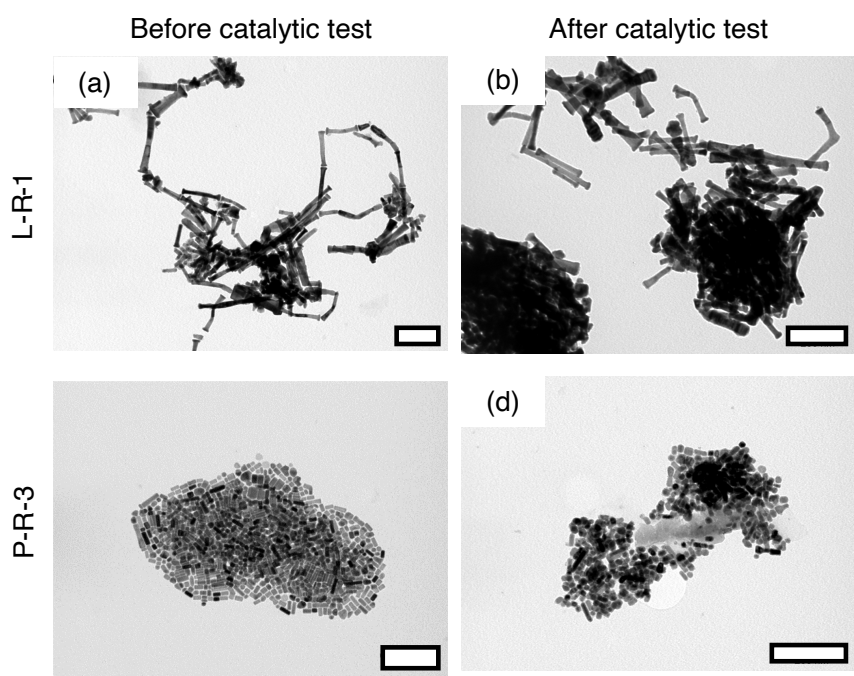

(d)

Figure 4. TEM images of catalysts L-R-1 $(a, b)$ and P-R-3 $(c, d)$, before $(a, c)$ and after catalytic test $(b, d)$. The scale bars stand for $200 \mathrm{~nm}$.

for two dried non-active catalysts (L-R-3 and P-R-2): (1) thermal treatment under vacuum (2) washing with ethanol, (3) $\mathrm{H}_{2}$ in situ pre-treatment before the reaction (see Experimental section). None of these pre-treatments improved the catalysts activity (Table 3). TGA- $\mathrm{N}_{2}$ performed after the treatments demonstrated that the first two strategies considered (thermal treatment under vacuum and washing of a dried sample with EtOH) failed at reducing the amount of ligands. The synthesis protocol was then modified in order to try to decrease the amount of ligands at the surface, by washing more intensively the nanoparticles recovered after synthesis but before the drying step. This last pre-treatment (labeled \#4 in Table 3) was performed on the P-R-2 and P-P samples, where the final washing was modified from 3 times with absolute ethanol to 6 with methanol and from 3 times with absolute ethanol to 12 times with methanol, respectively. TEM was used to control that the shape was not modified after this treatment (Figure S4). This more intensive washing decreased the residual amount of the palmitate ligands from $32 \mathrm{wt} \%$ to $12 \mathrm{wt} \%$ for P-R-2 sample, and from $44 \mathrm{wt} \%$ to $16 \mathrm{wt} \%$ for P-P sample (see Table $3)$, which corresponds to 1-2 monolayers of ligands on the surface of both samples. The corresponding catalytic performance improved - conversion increased from 3\% (100 $\mathrm{mol}_{\text {alcohol }} \mathrm{mol}_{\text {surface } \mathrm{Co}^{-1}}$ in TON) up to $19 \%$ (620 molalcohol mol $_{\text {surface }}$ $\left.\mathrm{Co}^{-1}\right)$, and from $16 \%\left(430 \mathrm{~mol}_{\text {alcohol }} \mathrm{mol}_{\text {surface }} \mathrm{Co}^{-1}\right.$ ) to $55 \%(990$

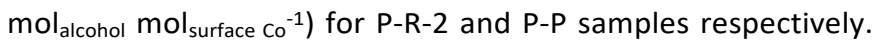
This further confirms the importance of the amount of decorating ligands in controlling the catalytic activity of the shaped nanoparticles.

Table 3. Effect of different pre-treatments of Co NPs: (1) thermal treatment under vacuum (2) washing with ethanol of the dried sample (3) $\mathrm{H}_{2}$ in situ pretreatment (4) additional washing with methanol during the synthesis of the catalysts. Reaction conditions: 2-octanol $\left(0.95 \mathrm{~mol} \mathrm{~L}^{-1}\right)$, decane, $145^{\circ} \mathrm{C}, 24 \mathrm{~h}$, inert atm, $\mathrm{m}_{\text {catalyst }}=25 \mathrm{mg}, \mathrm{n}_{\text {alcohol }}: \mathrm{n}_{\text {catalyst }}=100$. The amount of ligands was determined by TGA- $\mathrm{N}_{2}$ before and after the pre-treatments when possible.

${ }^{1}$ Weight loss according to TGA-N $\mathrm{N}_{2}$ measurements, equal to the mass of organic ligands in the sample n.a. - not available 
Noticeably, when the samples with a high coverage of ligands were used to perform the catalytic tests, the colour of the suspension evolved from colourless to light yellow/brown, which might be an indication of Co leaching. ICP-OES of the solutions after reaction (see Table S2) confirmed the presence of Co for all samples of the second group while this leaching was under the detection limit in the case of an active catalyst (L-R1). TGA analyses of the two spent catalysts showed that the amount of organic ligands protecting the samples decreased significantly after the reaction: from $32 \mathrm{wt} \%$ to $26 \mathrm{wt} \%$ for the inactive P-R-1 and from 10 wt\% to 6 wt\% for the active L-R-1. Even though the active catalyst was also losing some protecting ligands it can be assessed that a monolayer of ligands was still present on the metal surfaces, whereas the decrease of ligand content for the inactive catalyst was not large enough to improve its activity. To verify if the shape of the NPs was changing during the reaction, TEM analysis of two spent catalysts was performed. The corresponding images are presented in Figure 4. The shape of L-R-1 and P-R-3 is not drastically modified. An aggregation and a bluntness of the tips were mainly observed. The major difference before and after the catalytic test is for the P-R-3 sample where a grey zone appeared (Figure 4d, centre of the image), which we assigned to a $\mathrm{Co}$ (II) carboxylate phase (lamellar phase). ${ }^{29}$ It may originate from the leaching of Co NPs favoured by the excess of ligand or by the presence of some unreduced Co(II)-carboxylate precursors in the organic layers covering the Co NPs and can be related with the leached Co observed by ICP-OES of the solution.

\subsection{Structure sensitivity}

Among the active catalysts, namely those that are covered by roughly one to two monolayers or a bilayer of ligands, structure/activity relationships can be investigated plotting the catalytic activity per exposed site (TON) either as a function of the total number of sites (Figure $5 \mathrm{a}$ ) or as a function of the number of a given site (Figure $5 b$ for (0001) facets and Figure $5 c$ for $\{11-20\}$ and $\{11-21\}$ surfaces). These plots do not include $\mathrm{H}-$ $R$ since the surface area could not be established on that specific sample based on TEM. However, the P-R-2 and P-P samples that underwent extra washing before drying (pre-treatment \#4, see Table 3 ) are included as their surface coverage is below $20 \cdot 10^{-6}$ $\mathrm{mol} \mathrm{m} \mathrm{m}^{-2}$.

The TON is not constant as a function of the number of surface sites (Figure 5a) since it ranges from 600 to 1170 molalcohol mol $_{\text {surface }} \mathrm{Co}^{-1}$. This result suggests that since Co nanoparticles expose different types of sites in various extents, these sites must be differently active. It was then plotted as a function of the amount of exposed close packed (0001) facets (Figure 5b) and open type facets (namely $\{11-20\}$ and $\{11-21\}$, Figure $5 \mathrm{c}$ ). However, it is still not possible to observe a clear trend, even though the presence of ligands is limited to 1-2 monolayers. This is likely resulting from the complicated kinetics with variable induction periods (from few minutes to hours) and a probable variable poisoning (with a drop in $\mathrm{H}_{2}$ production even at rather low conversion, see Figure 2). As we already reported, DFT computations predict that the type of exposed facet can
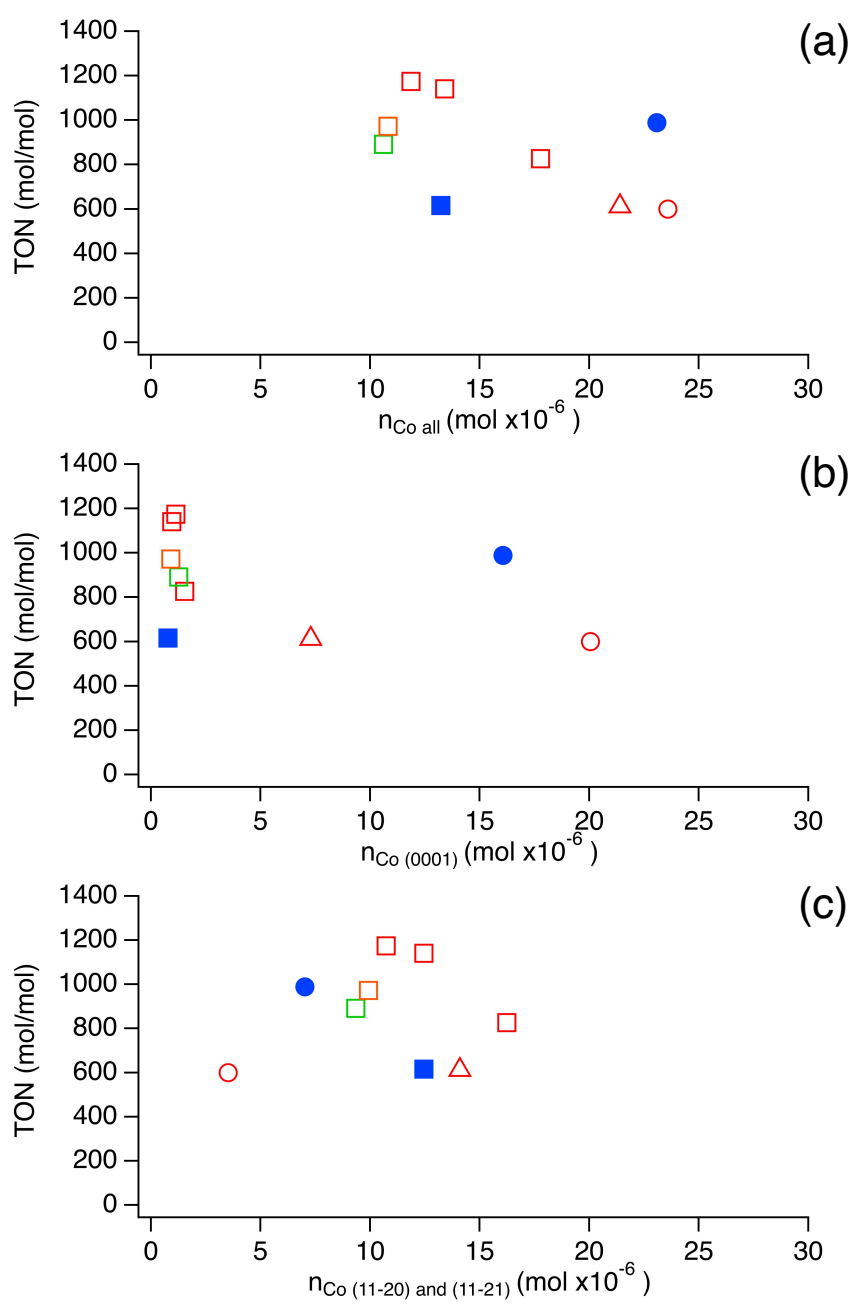

Figure 5. TON ( molalcohol $\mathrm{mol}_{\text {surface } \mathrm{co}^{-1}}$ ) of the catalysts as a function of the number of surface exposed Co $\left(10^{-6} \mathrm{~mol}\right)$ (a) all the surfaces are included (b) only the close-packed facet sites (0001) (c) only the opened facets sites (\{11-20\} and \{11-21\}). Each point corresponds to a catalytically active Co sample with ligand surface coverage $<20 \cdot 10^{-6}$ mol m$~^{-2}$ as found in Table 1 and Table 2) for the samples decorated by laurate (red), decanoate (orange) and octanoate (green). The palmitate (blue) samples were obtained after extra washing (Table 3). The shape of the symbol corresponds to the shape of the NPs: nanorods $(\square)$, diabolos $(\triangle)$, platelets $(\bigcirc)$.

influence the catalytic activity of metal, (11-20) facet being more active than close packed (0001) surface. ${ }^{54}$ Structure sensitivity of this reaction was also reported on $\mathrm{Cu}$, where stepped $\mathrm{Cu}$ surfaces are found to be more active than (111) facet for alcohol dehydrogenation both experimentally ${ }^{55}$ and computationally. ${ }^{56}$ However, in none of these reports the presence of surface ligands was taken into consideration.

\subsection{Understanding the role of ligands - DFT computations}

To rationalize the influence of the ligands, we determined the Gibbs free energy profiles of the alcohol dehydrogenation reaction with periodic DFT on the two mainly exposed facets, namely (11-20) and (0001), using isopropanol (iPrOH) as a model secondary alcohol. We compared the pristine surfaces with the ones decorated with model carboxylic ligands $\left(\mathrm{CH}_{3} \mathrm{COO}^{*}\right)$ with a similar coverage of roughly $7 \cdot 10^{-6} \mathrm{~mol} \mathrm{\textrm {m } ^ { - 2 }}$. More precisely, we took a coverage of $0.75 \mathrm{ML}\left(7.26 \cdot 10^{-6} \mathrm{~mol}\right.$ $\mathrm{m}^{-2}$ ) in acetate ligands (labeled A) on $\mathrm{Co}(11-20)$ and of $0.44 \mathrm{ML}$ 
$\left(6.98 \cdot 10^{-6} \mathrm{~mol} \mathrm{~m}^{-2}\right)$ on $\mathrm{Co}(0001)$. In the following, these decorated surfaces are named $0.75 \mathrm{~A}-\mathrm{Co}(11-20)$ and $0.44 \mathrm{~A}-$ Co(0001), respectively. Those ligands surface concentrations are lower than the experimental ones but they were chosen to leave access to few metal atoms, for the reaction to proceed. This corresponds to a local defect in layer of ligands that would generate a 'catalytic pocket' in analogy with enzymes.

Alcohol dehydrogenation is found to be slightly endergonic $(0.07 \mathrm{eV})$ in close agreement with the experimental Gibbs reaction energy for isopropanol dehydrogenation $(0.05 \mathrm{eV}) .^{74}$ This reaction requires the scission of two bonds, $\mathrm{O}-\mathrm{H}$ and $\mathrm{C}-\mathrm{H}$, to generate acetone. Depending on the ordering of these two dissociations, two pathways can be distinguished: the alkoxy path and the hydroxyalkyl path. In the alkoxy path, the $\mathrm{O}-\mathrm{H}$ bond breaking yields to an alkoxy intermediate, from which the $\mathrm{C}-\mathrm{H}$ bond scission takes place. The hydroxyalkyl path starts with the $\mathrm{C}-\mathrm{H}$ bond dissociation, leading to the formation of hydroxyalkyl intermediate, and continues with the $\mathrm{O}-\mathrm{H}$ scission. In agreement with the literature, ${ }^{54,75,76,77}$ the alkoxy path is systematically preferred over the hydroxyalkyl one for the alcohol dehydrogenation on all the Co surfaces investigated by us. The corresponding Gibbs free energy profiles and schematic representations of intermediates and transition states are shown in Figure 6 and S8 for the alkoxy and hydroxyalkyl pathways, respectively. with solid lines in Figure 6, towards the left and the right side respectively. On both surfaces, the adsorption of $\mathrm{iPrOH}$ is not stabilized, which will result in short contact time between the alcohol and the catalyst. The $\mathrm{O}-\mathrm{H}$ scission is clearly structure sensitive, with a $0.70 \mathrm{eV}$ barrier on (0001) that considerably drops to $0.10 \mathrm{eV}$ on (11-20). The structure sensitivity of the following $\mathrm{C}-\mathrm{H}$ scission is less striking with barriers of $0.62 \mathrm{eV}$ and $0.48 \mathrm{eV}$ on (0001) and (11-20) respectively. On both facets, iPrO is by far the most stable intermediate (and hence the resting state of the catalytic cycle) and as expected, it is more strongly adsorbed on the open type facet, but only by $0.12 \mathrm{eV}$. Similarly, hydrogen and acetone are adsorbed more strongly on this open surface (by $0.06 \mathrm{eV}$ and $0.45 \mathrm{eV}$, respectively). Hence, their desorption is less demanding from (0001) than from (11-20). However, the eased desorption of the products is not enough to make (0001) the most catalytically active facet. With both O$\mathrm{H}$ and $\mathrm{C}-\mathrm{H}$ bond breakings that are facilitated, the sites exposed on the Co(11-20) facet are more efficient than the ones exposed on Co(0001). This is also clearly shown by the resulting low energy span of $1.13 \mathrm{eV}$ on the open type surface, to be compared with $1.49 \mathrm{eV}$ on the compact one. ${ }^{\S}$

Now, a key question arises: how does the presence of carboxylic ligands change this picture? We already said that the preference for the alkoxy path is maintained. The Gibbs free energy profiles of the alcohol dehydrogenation on the decorated facets are

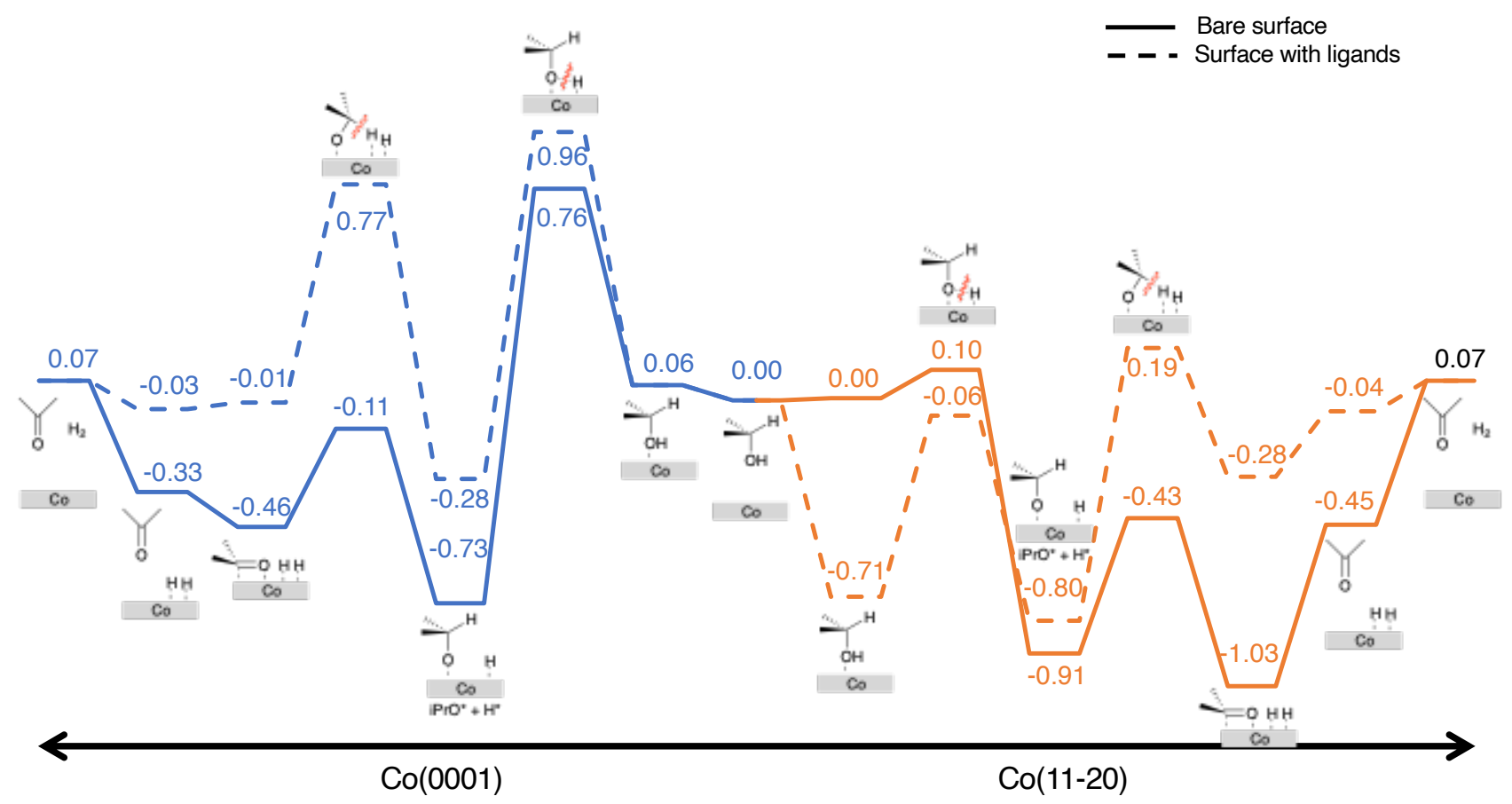

Figure 6. Gibbs free energy profiles (in eV) for iPrOH dehydrogenation via the alkoxy pathway on the Co(0001) facet (left side) and on the Co(11-20) facet (right side). Profiles with a solid line correspond to bare surfaces, dashed line to surface decorated with $\mathrm{CH}_{3} \mathrm{COO}$ ligands. The reference energy is the isolated iPrOH and the isolated surface. When a decorated surface is considered, this surface is the optimal decorated surface at the chosen coverage. Schematic drawings represent path stages.

Focusing on the favored alkoxy path, we start comparing the predicted activities of the two bare surfaces, Co(0001) and Co(11-20), which will be use a reference later when moving to the surfaces covered with carboxylic ligands. ${ }^{\ddagger}$ The corresponding energy profiles for the bare surfaces are shown superimposed in dashed lines to the ones of the pristine surfaces in Figure 6 for this alkoxy pathway. Surprisingly, even though the surfaces coverage with ligands is very similar, their presence globally destabilizes the reaction profile on (0001) while it affects the surface species in a contrasted manner on 
(a) $0.75 \mathrm{~A}-\mathrm{Co}(11-20)$
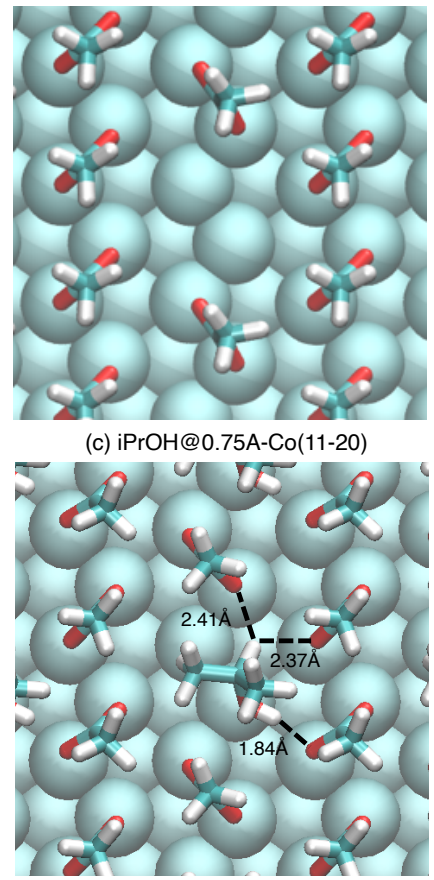

(c) $\mathrm{iPrOH} @ 0.75 \mathrm{~A}-\mathrm{Co}(11-20)$ (b) $0.44 \mathrm{~A}-\mathrm{Co}(0001)$

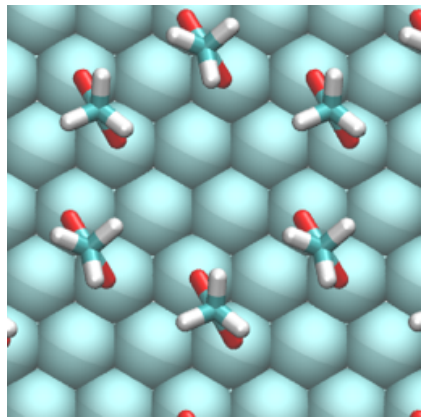

(d) iPrOH@0.44A-Co(0001)

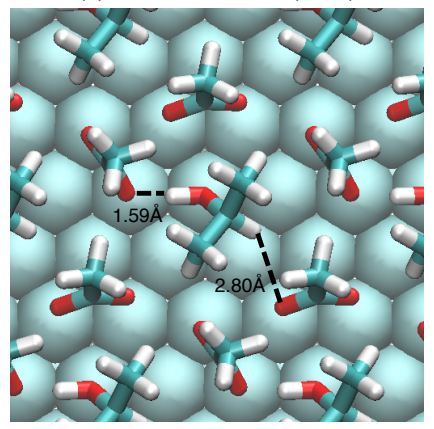

Figure 7. Optimized structures of: (a) $0.75 \mathrm{~A}-\mathrm{Co}(11-20)$ surface, (b) $0.44 \mathrm{~A}-\mathrm{Co}(0001)$ surface, (c) iPrOH@0.75A-Co(11-20) and (d) iPrOH@0.44A-Co(0001). Main distances are provided in $\AA$. Co is shown in cyan (ligh blue) balls. Acetate ligands and $\mathrm{iPrOH}$ are represented with sticks: $\mathrm{C}$ in blue, $\mathrm{O}$ in red, $\mathrm{H}$ in white.

the (11-20). Importantly, it results systematically in an energy span that is lower than for the surfaces without ligand decoration. Thanks to a stronger destabilization of the adsorption of the intermediate than of the $\mathrm{OH}$ scission transition state, the span falls from $1.49 \mathrm{eV}$ to $1.24 \mathrm{eV}$ on the (0001). With a destabilization of one of the intermediates $(H)$ and the products, the span decreases also on the most active (11-20) facet, from $1.13 \mathrm{eV}$ to $0.99 \mathrm{eV}$. What is worth to notice, the reduction of the energy span is not related to lower activation energies of the elementary steps, but to the (de)stabilization of reactant and products on the catalyst surface. In short, the catalytic activity is enhanced by the presence of the surrounding ligands and is still higher on the (11-20) facet than on the (0001) facet, but with a less contrasted difference, thereby likely limiting the possibility to observe experimentally the structure sensitivity of alcohol dehydrogenation using decorated shaped nanoparticles.

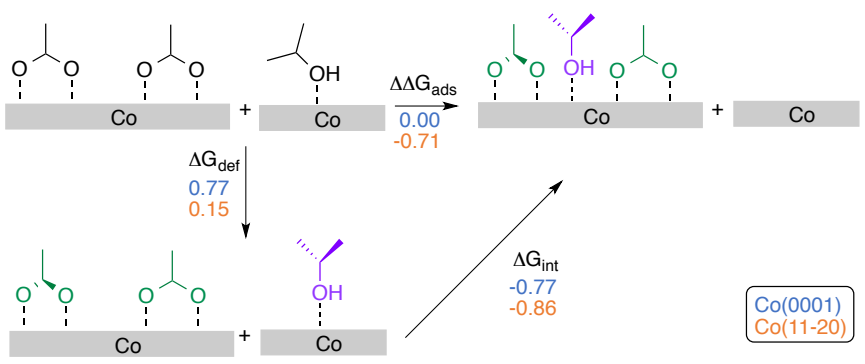

Scheme 1. Decomposition of the variation of Gibbs Free energy of adsorption of iPrOH on Co induced by the presence of acetate ligands $\left(\Delta \Delta \mathrm{G}_{\mathrm{ads}}\right)$ into deformation $\left(\Delta \mathrm{G}_{\mathrm{def}}\right)$ and interaction $\left(\Delta \mathrm{G}_{\text {int }}\right)$. The corresponding values are reported in $\mathrm{eV}$ for the $\mathrm{Co}(0001)$ and Co(11-20) surfaces in blue and orange, respectively. Details are reported in supplementary information (Table S4).
Let us now analyze in more details the impact of the ligands on a selected case. Strikingly, the adsorption of $\mathrm{iPrOH}$ is greater on $0.75 \mathrm{~A}-\mathrm{Co}(11-20)$ than on the corresponding bare surface by $0.71 \mathrm{eV}$, while it is almost not affected by the ligands on the $0.44 \mathrm{~A}-\mathrm{Co}(0001)$, as shown on Figure 6 . The origin can be tracked back through a decomposition into deformation and interaction terms of the variation in adsorption Gibbs free energies with and without ligands. This decomposition is schematically represented in Scheme 1 and the corresponding energies are provided in Table S4 in SI. On both surfaces, the interaction of the iPrOH with the catalytic pocket made of the metal surface and the surrounding ligands is favored by the formation of a $\mathrm{H}$ bond (see Figure $7 \mathrm{c}$ and $7 \mathrm{~d}$ ), with interaction energy of $-0.86 \mathrm{eV}$ and $-0.77 \mathrm{eV}$ on $0.75 \mathrm{~A}-\mathrm{Co}(11-20)$ and on $0.44 \mathrm{~A}-\mathrm{Co}(0001)$, respectively. This stabilization is counterbalanced by an important deformation penalty $(0.77 \mathrm{eV})$ for the ligands and the alcohol on the (0001) surface. This penalty can be related to the necessary change in adsorption position of the ligands upon alcohol adsorption, moving from a parallel orientation to a lessorganized configuration (see Figure $7 b$ vs $7 d$ ). On the other hand, the catalytic pocket is well adapted to adsorb the alcohol on the (11-20) with a very limited deformation cost $(0.15 \mathrm{eV})$, resulting in an overall stabilization (the ligands preserve their configurations in the presence of alcohol; see Figure 7a vs. 7c). The superior adaptability of the $0.75 \mathrm{~A}-\mathrm{Co}(11-20)$ catalytic pocket holds for all intermediates and transition states with a deformation cost that is systematically lower than for $0.44 \mathrm{~A}$ $\mathrm{Co}(0001)$. The highest deformation cost is to be paid for the C$\mathrm{H}$ scission $(>0.80 \mathrm{eV})$, with a limited interaction gain $(<0.50 \mathrm{eV})$, resulting in a systematic destabilization of the corresponding transition state. This can be related to the increase in space required by this transition state compared with the preceding iPrO intermediate. To adapt, the carboxylate ligands had even to adjust again their adsorption positions, diffusing to another adsorption site. This analysis opens the road to improve the catalytic pocket, the choice of the ligands combined with the appropriate facet appearing as an important dimension of the catalyst design. It also points out the importance of coadsorbates. In the case of the acceptor-less alcohol dehydrogenation reaction catalyzed by pristine $\mathrm{Co}$, the alkoxy intermediate is likely to play also a critical role since it is particularly stabilized by the formation of three Co-O bonds.

\section{Conclusion}

The 2-octanol dehydrogenation was found to be a very clean process when catalyzed by decorated Co NPs, leading to the production of 2-octanone and $\mathrm{H}_{2}$ exclusively. These heterogeneous catalysts are not stabilized on a support, but by an organic layer of carboxylate ligands attached to their surfaces. The ligands were used in the NPs synthesis, by the polyol process, to direct their shape, and are further protecting the samples. These unconventional heterogeneous catalysts were found to be very stable under the reaction conditions with no leaching of Co into the solution and no change in shape (platelets, diabolos and rods). The only cases where leaching was observed corresponded to samples with low activity. 
The catalytic performance was analyzed in regard to the intrinsic properties of shaped NPs i.e. type and amount of exposed facets and the presence of protecting ligands. The ligand length was varied from $\mathrm{C} 7$ to $\mathrm{C} 16$, but was not influencing the activity. The thickness of the ligand layer appeared to be much more important parameter. When a thick organic layer (roughly over 5 monolayers) was found on the NPs surfaces, the catalytic activity dropped dramatically. This organic layer may contain some unreduced $\mathrm{Co}$ (II)-carboxylate precursors or favors the re-oxidation of Co since an important leaching of Co was also observed in the solution after the catalytic test. The extra intensive washing following the synthesis of these NPs allowed to recover a good activity by limiting an organic layer thickness to 1 - 2 monolayers. This amount was systematically found on each active catalyst, whatever the shape and the ligand that were used. It appears to be sufficiently low to give access to the metallic surface for the reaction to proceed, but thick enough to prevent any agglomeration or strong shape modification during the catalytic tests.

Our computational investigations of this reaction on the two mainly exposed facets revealed that the open type facet is expected to be much more active than the compact one. This structure sensitivity prediction, made on pristine surfaces, is not in agreement with the experimental observations where no clear correlation could be found between the catalytic activity expressed in TON and the amount of open type facet sites, despite the large range covered by our various shaped NPs. However, further computational analysis of decorated surfaces evidenced that the carboxylate ligands are limiting the predicted difference in activity between the two types of surfaces, and thereby the predicted structure sensitivity. In addition, the number of accessible catalytic pockets can differ on one facet compared to the other, limiting a direct experimental comparison of the two types of surfaces. Interestingly, our DFT computations also revealed a strong participation of ligands in the reaction, in particular through $\mathrm{H}-$ bonding. This yields to a predicted increase of the catalytic activity for a give metallic site when surrounded by carboxylate ligands, both on the compact and the open surface. The catalytic pocket generated by these ligands is particularly well adapted to the alcohol dehydrogenation on the (11-20) facet where the necessary deformations are limited. This improved understanding of the role of the ligand in the catalytic cycle opens the road to design a bespoke catalytic pocket with an optimal choice of the ligands combined with the appropriate facet.

\section{Acknowledgements}

The work was done as a part of ANR TANOPOL project (ANR-15CE07-0011-01). This work was performed using HPC resources from GENCI-CINES (Grant 2018-A0050800609) and from the PSMN Data Center, which was financially supported by the SYSPROD project and AXELERA Pôle de Compétitivité.

\section{Conflicts of interest}

There are no conflicts to declare.

\section{Notes and references}

‡ In our previous work, ${ }^{54}$ we focused on the influence of the type of facet on the control of the chemoselectivity (primary vs. secondary alcohol) and reported the iPrOH dehydrogenation on bare $\mathrm{Co}(0001)$ and $\mathrm{Co}(11-20)$ surfaces. We improved here the level of calculation to better describe the influence of the (polar) carboxylate ligands: increase of the vacuum size over the surface up to $15 \AA$, inclusion of a dipole correction in z direction, inclusion of thermal effects (Gibbs free energies) for better comparison with experiments through the energy span model. These modifications do not change the overall picture of the activity of surfaces.

$\S$ To apply the energy span model, the Gibbs free reaction energy should be athermic or exergonic. Here, we predict a slightly endergonic reaction that we took as athermic.

1 R. A. Van Santen, Accounts Chem. Res., 2009, 42, 57-66.

2 J. Chen, W. Fang, Q. Zhang, W. Deng and Y. Wang, Chem. Asian J., 2014, 9, 2187-2196.

3 F. Pinna, Catal. Today, 1998, 41, 129-137.

4 J. R. Regalbuto, Ed., Catalyst preparation: science and engineering, Taylor \& Francis, Boca Raton, 2007.

5 M. B. Gawande, A. Goswami, F.-X. Felpin, T. Asefa, X. Huang, R. Silva, X. Zou, R. Zboril and R. S. Varma, Chem. Rev., 2016, 116, 3722-3811.

6 R. Xu, D. Wang, J. Zhang and Y. Li, Chem. Asian J., 2006, 1, 888893.

7 K. M. Bratlie, H. Lee, K. Komvopoulos, P. Yang and G. A. Somorjai, Nano Lett., 2007, 7, 3097-3101.

8 S.-H. Feng and G.-H. Li, in Modern Inorganic Synthetic Chemistry, Elsevier, 2nd edn., 2017, pp. 73-104.

9 B. Roldan Cuenya, Acc. Chem. Res., 2013, 46, 1682-1691.

10 D. I. Sharapa, D. E. Doronkin, F. Studt, J. Grunwaldt and S. Behrens, Adv. Mater., 2019, 31, 1807381.

$11 \mathrm{H}$. Lee, RSC Adv., 2014, 4, 41017-41027.

12 L. Liu and A. Corma, Chem. Rev., 2018, 118, 4981-5079.

13 P. Losch, W. Huang, E. D. Goodman, C. J. Wrasman, A. Holm, A. R. Riscoe, J. A. Schwalbe and M. Cargnello, Nano Today, 2019, 24, 15-47.

14 T. S. Rodrigues, A. G. M. da Silva and P. H. C. Camargo, J. Mater. Chem. A, 2019, 7, 5857-5874.

15 Z. Niu and Y. Li, Chem. Mater., 2014, 26, 72-83.

16 T. Chen and V. O. Rodionov, ACS Catal., 2016, 6, 4025-4033.

17 T. Yoskamtorn, S. Yamazoe, R. Takahata, J. Nishigaki, A. Thivasasith, J. Limtrakul and T. Tsukuda, ACS Catal., 2014, 4, 3696-3700.

18 J. Sá and J. W. Medlin, ChemCatChem, 2019, 11, 3355-3365.

19 M. A. Ortuño and N. López, Catal. Sci. Technol., 2019, 9, 51735185.

20 G. Kumar, E. Nikolla, S. Linic, J. W. Medlin and M. J. Janik, ACS Catal., 2018, 8, 3202-3208.

21 S. H. Pang, C. A. Schoenbaum, D. K. Schwartz and J. W. Medlin, Nat. Commun., 2013, 4, 1-6.

22 K. R. Kahsar, D. K. Schwartz and J. W. Medlin, J. Am. Chem. Soc., 2014, 136, 520-526.

23 D. González-Gálvez, P. Nolis, K. Philippot, B. Chaudret and P. W. N. M. van Leeuwen, ACS Catal., 2012, 2, 317-321.

24 G. Kumar, C.-H. Lien, M. J. Janik and J. W. Medlin, ACS Catal., 2016, 6, 5086-5094.

25 M. A. Ortuño and N. López, ACS Catal., 2018, 8, 6138-6145. 
26 F. Fiévet, S. Ammar-Merah, R. Brayner, F. Chau, M. Giraud, F. Mammeri, J. Peron, J.-Y. Piquemal, L. Sicard and G. Viau, Chem. Soc. Rev., 2018, 47, 5187-5233.

27 Y. Soumare, C. Garcia, T. Maurer, G. Chaboussant, F. Ott, F. Fiévet, J.-Y. Piquemal and G. Viau, Adv. Funct. Mater., 2009, 19, 1971-1977.

28 K. Mrad, F. Schoenstein, H. T. T. Nong, E. Anagnostopoulou, A. Viola, L. Mouton, S. Mercone, C. Ricolleau, N. Jouini, M. Abderraba, L.-M. Lacroix, G. Viau and J.-Y. Piquemal, CrystEngComm, 2017, 19, 3476-3484.

29 K. A. Atmane, C. Michel, J.-Y. Piquemal, P. Sautet, P. Beaunier, M. Giraud, M. Sicard, S. Nowak, R. Losno and G. Viau, Nanoscale, 2014, 6, 2682-2692.

30 R. K. Ramamoorthy, A. Viola, B. Grindi, J. Peron, C. Gatel, M. Hytch, R. Arenal, L. Sicard, M. Giraud, J.-Y. Piquemal and G. Viau, Nano Lett., 2019, 19, 9160-9169.

31 Q. Liu, X. Guo, Y. Li and W. Shen, Mater. Lett., 2009, 63, 14071409.

32 A. F. Dalebrook, W. Gan, M. Grasemann, S. Moret and G. Laurenczy, Chem. Commun., 2013, 49, 8735-8751.

33 H. Liu, H.-R. Tan, E. S. Tok, S. Jaenicke and G.-K. Chuah, ChemCatChem, 2016, 8, 968-975.

34 K. Kon, S. M. A. Hakim Siddiki and K. Shimizu, J. Catal., 2013, 304, 63-71.

35 G. Nicolau, G. Tarantino and C. Hammond, ChemSusChem, 2019, 12, 4953-4961.

36 R. Karvembu and S. Priyarega, React. Kinet. Catal. Lett., 2006, 88, 333-338.

37 W.-H. Kim, I. S. Park and J. Park, Org. Lett., 2006, 8, 2543-2545.

38 K. Kon, W. Onodera, T. Toyao and K. Shimizu, Catal. Sci. Technol., 2016, 6, 5864-5870.

39 Y. Sawama, K. Morita, T. Yamada, S. Nagata, Y. Yabe, Y. Monguchi and H. Sajiki, Green Chem., 2014, 16, 3439-3443.

40 W. Fang, Q. Zhang, J. Chen, W. Deng and Y. Wang, Chem. Commun., 2010, 46, 1547-1549.

41 W. Fang, J. Chen, Q. Zhang, W. Deng and Y. Wang, Chem-Eur J., 2011, 17, 1247-1256.

42 T. Mitsudome, Y. Mikami, H. Funai, T. Mizugaki, K. Jitsukawa and K. Kaneda, Angew. Chem. Int. Edit., 2008, 47, 138-141.

43 K. Shimizu and A. Satsuma, J. Jpn. Petrol. Inst., 2011, 54, 347360.

44 A. Bayat, M. Shakourian-Fard, N. Ehyaei and M. Mahmoodi Hashemi, RSC Advances, 2015, 5, 22503-22509.

45 K. Shimizu, K. Sugino, K. Sawabe and A. Satsuma, Chem-Eur J., 2009, 15, 2341-2351.

46 J. M. Conesa, M. V. Morales, C. López-Olmos, I. RodríguezRamos and A. Guerrero-Ruiz, Appl. Catal. A-Gen., 2019, 576, 5464.

47 T. Mitsudome, Y. Mikami, K. Ebata, T. Mizugaki, K. Jitsukawa and K. Kaneda, Chem. Commun., 2008, 4804-4806.

48 D. Damodara, R. Arundhathi and P. R. Likhar, Adv. Synth. Catal., 2014, 356, 189-198.

49 Y. Zhu, M. Shen, Y. Xia and M. Lu, Appl. Organomet. Chem., 2015, 29, 152-156.

50 K. Shimizu, K. Kon, K. Shimura and S. S. M. A. Hakim, J. Catal., 2013, 300, 242-250.

51 H. Chen, S. He, M. Xu, M. Wei, D. G. Evans and X. Duan, ACS Catal., 2017, 7, 2735-2743.

52 K. Shimizu, K. Kon, M. Seto, K. Shimura, H. Yamazaki and J. N. Kondo, Green Chem., 2013, 15, 418-424.
53 J. Yi, J. T. Miller, D. Y. Zemlyanov, R. Zhang, P. J. Dietrich, F. H. Ribeiro, S. Suslov and M. M. Abu-Omar, Angew. Chem. Int. Edit., 2014, 53, 833-836.

54 A. Viola, J. Peron, K. Kazmierczak, M. Giraud, C. Michel, L. Sicard, N. Perret, P. Beaunier, M. Sicard, M. Besson and J.-Y. Piquemal, Catal. Sci. Technol., 2018, 8, 562-572.

55 X. He, Y. Wang, X. Zhang, M. Dong, G. Wang, B. Zhang, Y. Niu, S. Yao, X. He and H. Liu, ACS Catal., 2019, 9, 2213-2221.

56 R. A. Hoyt, M. M. Montemore, E. C. H. Sykes and E. Kaxiras, J. Phys. Chem. C, 2018, 122, 21952-21962.

57 L. Lutterotti, S. Matthies and H.-R. Wenk, Newsletter of the CPD, 1999, 21, 14-15.

58 G. Kresse and J. Hafner, Phys. Rev. B, 1993, 47, 558-561.

59 J. P. Perdew, K. Burke and M. Ernzerhof, Phys. Rev. Lett., 1996, 77, 3865-3868.

60 S. N. Steinmann and C. Corminboeuf, J. Chem. Phys., 2011, 134, 044117.

61 S. N. Steinmann and C. Corminboeuf, J. Chem. Theory Comput., 2011, 7, 3567-3577.

62 P. E. Blöchl, Phys. Rev. B, 1994, 50, 17953-17979.

63 G. Kresse and D. Joubert, Phys. Rev. B, 1999, 59, 1758-1775.

64 H. J. Monkhorst and J. D. Pack, Phys. Rev. B, 1976, 13, 51885192.

65 G. Henkelman, B. P. Uberuaga and H. Jónsson, J. Chem. Phys., 2000, 113, 9901-9904.

66 D. Sheppard, R. Terrell and G. Henkelman, J. Chem. Phys., 2008, 128, 134106.

67 P. Fleurat-Lessard, .

68 G. Henkelman and H. Jónsson, J. Chem. Phys., 1999, 111, 70107022.

69 J. Kästner and P. Sherwood, J. Chem. Phys., 2008, 128, 014106.

70 F. Fiévet, S. Ammar-Merah, R. Brayner, F. Chau, M. Giraud, F. Mammeri, J. Peron, J.-Y. Piquemal, L. Sicard and G. Viau, Chem. Soc. Rev., 2018, 47, 5187-5233.

71 T. Maurer, F. Zighem, F. Ott, G. Chaboussant, G. André, Y. Soumare, J.-Y. Piquemal, G. Viau and C. Gatel, Phys. Rev. B, 2009, 80, 064427.

72 K. Ait Atmane, F. Zighem, Y. Soumare, M. Ibrahim, R. Boubekri, T. Maurer, J. Margueritat, J.-Y. Piquemal, F. Ott, G. Chaboussant, F. Schoenstein, N. Jouini and G. Viau, J. Solid State Chem., 2013, 197, 297-303.

73 C. A. Schoenbaum, D. K. Schwartz and J. W. Medlin, Accounts Chem. Res., 2014, 47, 1438-1445.

74 E. Buckley and E. F. G. Herington, T. Faraday Soc., 1965, 61, 1618-1625.

75 J. Zaffran, C. Michel, F. Delbecq and P. Sautet, Catal. Sci. Technol., 2016, 6, 6615-6624.

76 W. Luo and A. Asthagiri, J. Phys. Chem. C, 2014, 118, 1527415285.

77 J. E. Sutton and D. G. Vlachos, Ind. Eng. Chem. Res., 2015, 54, 4213-4225. 